\title{
A Category Approach for Reproductive Effects of Phthalates
}

\section{Evelin Fabjan ${ }^{1}{ }^{1}$, Etje Hulzebos ${ }^{*}{ }^{2}$, W. Mennes ${ }^{2}$ and A. H. Piersma ${ }^{2}$}

${ }^{1}$ Utrecht University, Institute for Risk Assessment Sciences, Utrecht, The Netherlands.

${ }^{2}$ National Institute of Public Health and Environment, Bilthoven, The Netherlands. *Correspondence: Etje Hulzebost, National Institute of Public Health and Environment, PO Box 1, 3720 BA, Bilthoven, The Netherlands; E-mail: etje.hulzebos@rivm.nl

\begin{abstract}
In regulatory toxicology, the experimental assessment of reproductive toxicity is one of the most costly endpoints to perform. Categorizing chemicals is an approach that can be used to reduce animal tests in risk assessments of chemicals, for example, via REACH (Registration, Evaluation, and Authorization of Chemicals). The category approach was tested for reproductive toxicity with a group of 10 ortho-phthalate esters, with different side chain lengths. Three orthophthalates were used for testing the category. Phthalates with side-chain lengths C4 to $\mathrm{C} 6$ that are commonly known to cause reproductive effects were included, as well as the recently discovered mechanism that indicates antiandrogenic effects. The differences in physicochemical properties, absorption rates, and metabolism between the phthalates investigated could not fully explain the difference in reproductive toxicity. It was concluded that phthalates with the alkyl side-chain length from C4 to C6 produce similar severe reproductive effects in experimental animals. It is expected that phthalates included in the tight boundaries of the proposed category would all show severe reproductive effects, especially the antiandrogenic effects. Further testing might not be needed for phthalates within these boundaries. If necessary, limited testing could focus on the critical endpoints. Detailed mechanistic information is needed on phthalates to apply the categories for regulatory toxicology.

${ }^{\dagger}$ Both authors contributed equally to this article.
\end{abstract}

The aim of this article is to test the "commonly accepted" assumption, introduced by Foster et al. (1982), that ortho-phthalates with side chains of length C4 to C6 produce reproductive effects in the light of the category approach and necessary requirement described in the guidance of the Organization for Economic Cooperation and Development (OECD, 2004). A more defined category will be based on recent reproductive toxicity data, the developed mechanism of action (e.g., Ema and coworkers, 2000, 2002, 2003), and the evaluations of several regulatory agencies. This article tries to link the most recent research on the mechanistic background of the reproductive effects of the ortho-phthalates with the regulatory needs for category approaches to limit animal testing for the most costly endpoint (Van Der Jaght et al., 2004).

In regulatory toxicology, along with carcinogenicity studies, the experimental assessment of reproductive toxicity including fertility and developmental toxicity requires one of the most costly, time-consuming, and complex endpoints.

Furthermore, performance of these studies requires use of the highest number of test animals (Höfer et al., 2004; Van Der Jaght et al., 2004). At the moment there is no validated battery of alternative tests that would cover all different aspect of the reproductive cycle (ECVAM, 2002). There are relatively few (Q)SARs [(quantitative) structure-activity relationships] for predicting reproductive toxicity, and few computer programs available (TOPKAT, CASE, DEREKfW) can be and are to some extent used for this purpose (Hulzebos et al., 2001; Hulzebos 
and Posthumus, 2003). Therefore, more research and development in the area of alternative methods is required in order to achieve reduction and/or replacement of animal testing in the future (ECVAM, 2002; Van Der Jaght et al., 2004).

In the European Union (EU), various types of chemicals, in terms of intended use, are subjected to different legislations that aim to protection of human health and the environment. Current EU legislation for industrial chemicals, for both new and existing chemicals, requires risk assessment to be performed for these substances. However, new and existing chemicals follow two different procedures in order to come to a comprehensive risk assessment. For new substances (substances that were not on the EU market before 1981), a premarketing notification accompanied by the so-called "base set" of data is required, which depends on the tonnage of a chemical intended to be put on the market. Based on this, a risk assessment can be carried out, if necessary. On the other hand, for existing chemicals, risk assessment is carried out for a number of selected substances, which are put on priority lists, and only for those is a "base set" or equivalent data package required. Thus, new and existing chemicals are not subjected to the same testing requirements. Risk assessment for existing chemicals is a very time-consuming and complex procedure, due to, among other reasons, lack of adequate minimal data required to carry out a risk assessment (Bodar et al., 2002). Nevertheless, a number of detailed, high-quality risk assessments for existing substances were produced under the current legislation. Unfortunately, there is at the moment still a large number of marketed chemicals for which potential risk for human health and the environment has not yet been assessed and for which only very limited amounts of data are available.

To speed up this process, national and international initiatives are taking place for a new risk assessment procedure for chemicals on the EU market. In this respect, a new policy was proposed by the European Commission in which new and existing chemicals put on the market would be subjected to the same requirements (European Commission, 2003). The new proposed system is called REACH (Registration, Evaluation, and Authorization of Chemicals). It is expected that under this new policy, for a high number of chemicals, toxicological and ecotoxicological data will have to be generated, to a great extent also by performing animal testing. However, one of the objectives of the new policy is also a reduction of animal testing and reduction of costs for the industry. It is intended to achieve this through data sharing by the industry, by developing the so-called tailormade testing strategies, and by promotion of nonanimal testing and other alternative methods for identification of hazardous properties of chemicals (ECB, 2001b; European Commission, 2003; Enterprise DG and Environment DG, 2004).

In view of initiatives mentioned, it is expected that alternatives to animal testing such as in vitro methods, read-across approaches, (Q)SARs [(quantitative) structure-activity relationships], and other computer-based methods for predicting toxicity and ecotoxicity are going to play an important role not only for the priority setting of chemicals that will need further assessment but also for hazard and risk assessment purposes (ECVAM, 2002; Pedersen et al., 2003; Van Der Jaght et al., 2004).

In a recent report issued by the European Commission (Van Der Jaght et al., 2004), it was estimated that approximately 3.9 million testing animals would be additionally needed after introduction of REACH in case no alternative methods would be accepted by the regulatory authorities. By accepting the alternative methods this number could potentially be reduced by 1.3 to 1.9 million animals. In the same report it was also estimated that around $60 \%$ of the test animals would be required for reproductive toxicity studies, for two-generation reproductive toxicity studies, and for the developmental toxicity tests. 
Read-across and grouping of chemicals into categories is one of the approaches that has already been used in national and international procedures of safety and risk assessments of chemicals (Hanway and Evans, 2000; Combes et al., 2003) and is expected to play an important role also in the future REACH system. Furthermore, grouping of chemicals in categories may also be one of the first steps toward identification of structural alerts for different specific endpoints. SARs may be used as one of the criteria in the process for grouping chemicals in categories.

For the purpose of this article, the term "read across" refers to interpolation of toxicological properties of a given substance from chemically closely related substances with known toxicological properties.

In the U.S. Environmental Protection Agency (U.S. EPA) manual for investigation of HPV (high production volume) chemicals (1999), a chemical category is defined as "a group of chemicals whose physicochemical and toxicological properties are likely to be similar or follow a regular pattern as a result of structural similarity." Based on these structural similarities, predictions could be made for physicochemical properties, environmental fate and effects, and/or human health effects. The similarities may be based on a common functional group or the likelihood of common precursor and/or breakdown products, which result in structurally similar chemicals and incremental and constant change across the category. If the available information from the tests shows that the chemicals in a category behave in a similar and predictable manner, interpolation and/or extrapolation can be used to assess the chemicals instead of conducting additional tests.

The definition for a structure-activity relationship (SAR) in the OECD manual for investigation of HPV chemicals (OECD, 2004) is the following: "a SAR is the relationship of the molecular structure of a chemical with a physicochemical property, environmental fate attribute, and/or specific effect on human health or an environmental species. These correlations may be qualitative (simple SAR) or quantitative (quantitative SAR, or QSAR)." According to Walker et al. (2003), three elements comprise a relationship: (1) a descriptor (this can be a physical or chemical property), (2) an endpoint being predicted (physical or chemical property, or biologic activity), and (3) a derived relationship between the descriptors and the endpoint.

\section{METHODOLOGY}

The available U.S. EPA (1999) and OECD (2004) guidance on category approach has been used to arrive at a definition and description of a category. A literature search was performed to assess whether a similar attempt to define a category for reproductive effects of phthalates has already been made and to gather the available information on reproductive toxicity of these substances, especially after oral exposure. Care was taken to choose phthalates for which a national or international evaluation was available. A selection of 10 ortho-phthalates was made based on the available evaluations and on different side-chain lengths of the substances, in order to be able to determine the importance of the side-chain length for reproductive toxicity.

Then the information on physicochemical properties, oral absorption, metabolism, general toxicity, and specifically reproductive toxicity was summarized, in order to have an overview of the properties of the substances investigated and to facilitate the identification of similarities and differences between the substances and if possible to group them.

Based on this information, a category was proposed for certain phthalates. As the effects on sexual development of the males appeared to be the most critical effects, when grouping the phthalates, more emphasis was given to these effects. At the end, the domain of the category was checked by gathering the available 
information for a number of other ortho-phthalates and some phthalates with the esters in meta and para positions.

\section{Category Approach, SARs, QSARs}

\section{Current Use of the Category Approach and (Q)SARs to Assess Human Health Effects}

The category approach and adequately validated (Q)SARs can be used for prioritization, for prediction of effects when experimental data are lacking, as support for developing testing strategies, and for classification and labeling of chemicals.

At a workshop on regulatory acceptance of (Q)SARs for human health and environmental endpoints (ECETOC, 2002) an overview on the use of QSARs for regulatory purposes was made; it was recognized that the use up to that point was limited and that there is a need for a framework, which would serve as support for industry and regulators when using QSARs in decision making. Especially for SARs concerning human health effects there is a lack of criteria and guidance to assess their validity. Nevertheless, SARs and QSARs have been accepted and used for priority setting, identification of families of chemicals and assessing categories, prediction of some health effects, and classification and labeling by some regulatory agencies in the EU, the United States, Canada, and Australia (ECETOC, 2002; Cronin et al., 2003).

For reproductive/developmental toxicity, (Q)SARs are only occasionally used, because of the very limited database available and the complexity of these endpoints (ECETOC, 2002). For the prediction of developmental effects in particular, the analysis of chemical classes can be useful (Cronin et al., 2003).

In the European Union, the Technical Guidance Document (ECB, 2003b) includes a chapter with guidance on use of QSARs for environmental risk assessment, but no guidance is given for use of (Q)SARs for human health effects, except for organophosphates. However, some regulatory authorities such as the Danish EPA (2001), the UK HSE, the German BgVV, and RIVM in The Netherlands (ECETOC, 2002; Hulzebos and Posthumus, 2003) are using them in the process of evaluation and risk assessment of chemicals.

The category approach and SARs are used under the U.S. EPA HPV Chemical Challenge Program (Challenge Program), in which the chemical industry voluntarily compiles screening information data sets (SIDS) for chemicals on the U.S. HPV list (about 2800 HPV chemicals reported) (U.S. EPA, 1999).

The SIDS have also been internationally agreed upon by member countries of the OECD and are used to provide basic information needed for an initial assessment of the HPV chemicals on the OECD HPV list, in which more than 5000 chemicals are listed. Due to this large number of HPV chemicals, there is a need to reduce animal testing as much as possible. For this purpose, when scientifically justifiable, category approaches and SARs are used (OECD, 2004).

\section{Guidance on the Category Approach and Use of SARs in the Assessment of Human Health Effects of Chemicals}

There is relatively little guidance on the use of the category approach and SARs for the assessment of effects of chemicals on human health. Currently two documents, very similar in content--a draft document prepared by the U.S. EPA (1999) and a manual issued by the OECD-are available (OECD, 2004). Some guidelines for proper development and use of QSARs are also given in a recent paper prepared by Walker et al. (2003).

A review on the international regulatory use of QSARs to predict human health was made by Cronin et al. (2003). There is no specific guidance for the use of SARs in assessing mammalian toxicity. The OECD manual (OECD, 2004) lists 
some examples of the potential use of SARs: groups of isomers with similar SAR profiles; close homologues; and availability of information on precursors, breakdown and metabolites/degradation products of specific chemicals. In summary, it can be said that a general outline is given; however, establishing a category is still a case-by-case procedure.

\section{Phthalates-General Overview}

Phthalates are ubiquitous industrial chemicals that are used, among other ways, in consumer products (soaps, shampoos, and other cosmetics), plastics (including food packaging), paints, enteric coatings in some medications, and pesticide formulations.

Phthalates are substances with diester structure, containing a benzene ring, two carbonyl groups, and two alcohol groups. They are synthesized from phthalic anhydride and an alcohol (or alcohol mixture). In general, the term phthalate esters is used to address the ortho form of benzenedicarboxylic acid (Thomas and Thomas, 1984). The meta and para structural configurations are known as isophthalates and terephthalates, respectively (Thomas and Thomas, 1984) (Figure 1).<smiles>COCCOC(=O)c1ccccc1C(=O)OC</smiles><smiles>[R]OC(=O)c1cccc(C(=O)OC)c1</smiles>



ortho meta

para

FIG. 2

\section{General} metabolism pathways for phthalates (adopted by Silva et al., 2003).<smiles>COC(=O)c1ccccc1C(=O)O[Hg]</smiles>

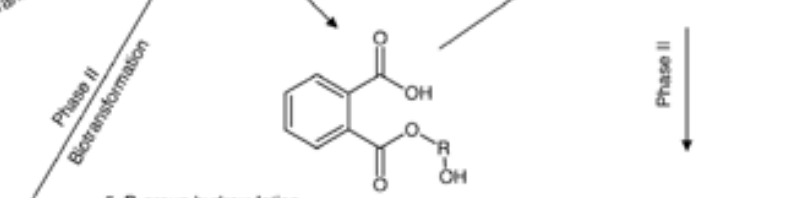

<smiles>[2H]OC(=O)c1ccccc1C(=O)OC1OC(C(C)=O)C(O)C(O)C1O</smiles><smiles>CC(=O)C1OC(OC(=O)c2ccccc2C(=O)OP=O)C(O)C(O)C1O</smiles>

4. Monoester phenalme givauronide 
When incorporated in a polymer matrix (e.g., as a plasticizer), phthalates are not covalently bound to the polymer and therefore are fairly easily released from products to air, water, saliva, blood, food, and other extracting material (DiGangi et al., 2002). Because of the extensive use of these products, humans are at potential risk for exposure to phthalates. Some phthalates and their metabolic products are known to cause reproductive and developmental toxicity in laboratory animals. Specifically, exposure in utero or during lactation to certain dialkyl phthalates has been shown to affect the sexual development, especially of male pups (ECB, 2001a, 2004a, 2004b). Measurable concentrations of metabolites of certain phthalates, such as monoethyl phthalate, monobutyl phthalate and monoethylhexyl phthalate, were found in human amniotic fluid, suggesting that in utero exposure to phthalates occurs (Silva et al., 2004b).

Phthalate esters are generally well absorbed in the gastrointestinal tract (Kluwe et al., 1982; IPCS, 2003; ECB, 2001, 2003a, 2003b, 2004a, 2004b; NTP-CEHR, 2003b, 2003c; OECD-HPV, 2004a). When orally ingested, dialkyl phthalates are probably absorbed from the gut primarily in the form of their monoester hydrolysis products. It appears that hydrolysis of the first ester group occurs much more readily than the hydrolysis of the second (Kluwe, 1982). The shortchain alkyl congeners are then generally further more readily hydrolyzed in the intestine than the long-chain alkyl congeners (Kluwe, 1982). Any absorbed diesters may be converted into monoesters in phase I biotransformation. Subsequently, the monoesters can be excreted in the urine unchanged, or they can undergo further biotransformation in which glucuronide conjugates or alternatively more hydrophilic oxidative products are produced (Silva et al., 2003).

In animal studies, some phthalates show a variety of toxic effects after chronic or in some cases also after short-term exposures. The effects observed included damage to liver (including peroxisome proliferation and carcinogenicity), kidney and thyroid (IPCS, 2003; ECB, 2001, 2003a, 2003b, 2004a, 2004b; NTP-CEHR, CEHR, 2003b, 2003c; OECD-HPV, 2004a). However, the most severe and worrisome adverse effects observed appear to be effects on reproduction and development. Results from a series of animal studies suggest that the monoester metabolite (which usually is also a major metabolite) of the parent compound is responsible for adverse reproductive and developmental effects of phthalates (ECB, 2001, 2004a, 2004b). Some of the reproductive effects observed in animal studies are decreased fertility in both sexes, altered hormone levels, reduced survival of offspring, and fetal defects. In developing males, some phthalates cause Sertoli and Leydig cell damage, female-like areolas/nipples, reduced anogenital distance (AGD), undescended testes, hypospadias, altered hormone levels, prostate damage, testicular atrophy, and reduced sperm production and motility (ECB, 2001, 2004a, 2004b; DiGangi et al., 2002).

There appears to be a generally accepted assumption that only ortho-phthalates with a specific side-chain length cause reproductive effects. Foster et al. (1982) concluded that in order for a phthalate ester (PAE) to produce testicular atrophy, the ester must be in the ortho position and of a specific chain length. In fact, in his study of testicular effects and changes in zinc concentration in rats after exposure to dialkyl phthalate esters with different side-chain lengths, only C4, C5, or C6 di-n-alkyl phthalates produced testicular toxicity in rats, while other diesters tested with shorter and longer side chains did not (Foster et al., 1980).

\section{Phthalates and Human Reproduction}

Due to clear evidence of adverse effects caused by endocrine-disrupting chemicals in laboratory animals and wildlife, there has been, in recent years, growing concern that exposure to such chemicals in the environment presents a serious threat also to human reproduction and development. In the report "Global Assessment of the State-of-the-Science of Endocrine Disruptors" prepared by 
IPCS (2002), the endocrine disruptor was defined as "an exogenous substance or mixture that alters function(s) of the endocrine system and consequently causes adverse health effects in an intact organism, or its progeny, or (sub)populations."

In animal studies, some of the "most important" potential adverse effects of phthalates-in particular, effects on sexual differentiation in male fetuses-were discovered only recently, due to application of reproduction/developmental toxicity study protocols in which exposure is extended in utero up to the end of gestation and in some cases also to the lactation period (Mylchreest et al., 1999; Park et al., 2002; Higuchi et al., 2003; Sharpe and Irvine, 2004). The reproductive-tract malformations observed after exposure to certain phthalates were similar to those observed after exposure to known antiandrogens such as vinclozolin and flutamide (Mylchreest et al., 1999a). However, it seems that the antiandrogenic effects observed after exposure to phthalates are not mediated by interaction with the androgen receptor (AR), as it is the case for some other known potent antiandrogens (Mylchreest et al., 1999; Parks et al., 2000). Therefore, they might not be identified by some receptor-based in vitro tests.

Although there is at the moment no firm evidence on direct causal association between low-level exposure to endocrine-disrupting chemicals and adverse health effects in humans, the increased incidence of some hormone-dependent disorders in the past decades, such as breast cancer and the postulated testicular dysgenesis syndrome (TDS), causes concern, that there could be an association to exposure to endocrine disruptors in the environment (Barlow et al., 1999; Skakkebæk et al., 2001; Damstra et al., 2002; Sharpe and Irvine, 2004). Due to effects that certain phthalates produce in experimental animals and due to their wide use, phthalates could be among the substances of concern in this respect.

As described by Skakkebæk et al. (2001), testicular dysgenesis syndrome comprises low sperm counts, testicular cancer, cryptorchidism, and hypospadias and is thought to be caused by disruption of development (abnormal function of Leydig and Sertoli cells) during fetal life. Recent animal studies on phthalates show that there is a remarkable similarity between the effects these substances cause in the testis of experimental animals and those in the human dysgenic testis (Sharpe, 2001; Fisher et al., 2003; Fisher, 2004).

According to Sharpe (2001), an important lesson learned from the phthalate studies is also that environmental chemicals that have the potential to alter endogenous hormone production and metabolism may pose a greater risk than many weak, receptor-mediated endocrine disruptors. In fact, until recently, most of the attention has been on the latter substances.

Recent studies show that in utero exposure to phthalates occurs to some extent also in humans, as measurable amounts of monoethyl phthalate, monobutyl phthalate, and monoethylhexyl phthalate were found in human amniotic fluid (Latini et al., 2003; Silva et al., 2004b). In a study where serum DEHP and MEHP concentrations were measured in the cord blood of 84 newborns, detectable levels of DEHP/MEHP were present in most of the examined newborns at birth and this was associated also with shorter pregnancy duration (Latini et al., 2003). Furthermore, exposure studies conducted in the last few years indicate that exposure to these substances might be higher and more common than had been previously thought and that some individuals might have considerably higher exposures than average (Blount et al., 2000; Colon et al., 2000; DiGangi et al., 2002; Koch et al., 2003; Silva et al., 2004a; Hauser et al., 2004). This certainly raises some concern, especially when taking into account that because of the wide use of these substances, people might be exposed during their entire lifetime and to combinations of various substances at the same time. 


\section{SELECTION AND PROPERTIES OF SELECTED PHTHALATES}

For the category approach, 10 ortho-phthalate esters were selected. The selection was made based on the availability of evaluation reports prepared in various international programs. The decision to choose substances that have to some extent already been evaluated, nationally or internationally, was taken to minimize the uncertainty regarding the identification of reproductive effects. Another criterion for selection was the length of the side chains, as the intention was to determine the importance of the length of the side chain for reproductive toxicity of these substances. Thus, a selection of ortho-phthalates with different lengths of the alkyl side chains was made (Table 1). Five phthalate esters were evaluated or are in the process of evaluation within the EU existing chemicals program (DBP, BBP, DEHP, DINP, and DIDP), two phthalates for which limited information was available were evaluated in the U.S. NTP-CEHR program (DnHP and DnOP), one phthalate ester was evaluated by IPCS (DEP), and two others were evaluated in the OECD-HPV chemicals program: Di-phC10 (C7 backbone) and DiC9-11.

TABLE 1 List of selected phthalates

Substance name (abbreviation)

Reference

Dibutyl phthalate (DBP)

ECB, 2004b

Benzyl butyl phthalate (BBP)

ECB, 2004a

Bis(2-ethylhexyl) phthalate (DEHP)

ECB, 2001

Di-"isononyl" phthalate (DINP)

ECB, 2003a

Di-"isodecyl" phthalate (DIDP)

ECB, 2003b

Di-n-hexyl phthalate (DnHP)

NTP-CEHR, $2003 b$

Di-n-octyl phthalate (DnOP)

NTP-CEHR, $2003 c$

Diethyl phthalate (DEP)

IPCS, 2003

Bis(2-propylheptyl) phthalate (DiphC10)

OECD-HPV, $2004 a$

1,2-Benzenedicarboxylic acid, DiC9-11 branched and linear alkyl OECD-HPV, esters (DiC9-11)

$2004 a$

In Appendix 1 the selected phthalates are listed in a table, with the respective diester structural formulas and of their monoester metabolites. The order of the list is based on the length of the side chains and molecular weight. Furthermore, some information on physicochemical properties, oral absorption, and metabolism after oral absorption is given. Structural formulas of diesters were drawn based on the structural formulas were derived with the EPIWIN 1.13 program (http://www.epa.gov/oppt/exposure/docs/episuitedl.htm). The information listed in the table was, if not otherwise referenced, summarized from the respective evaluation reports of single phthalates already referenced in Table 1.

DEP, DBP, BBP, DnHP, DEHP, DiphC10, and DnOP are "well-defined phthalates," DINP and DIDP are complex mixtures containing mainly $\mathrm{C}_{9}$ and $\mathrm{C}_{10}$ branched 
isomers, respectively (ECB, 2003a, 2003b), and DiC9-11 contains branched and linear esters (OECD-HPV, 2004a). Two structural formulas are presented for DINP and DIDP. In this case of DINP, in the EU Risk Assessment Report, three different DINPs were identified under two CAS numbers, and two structural formulas were recovered under these two CAS numbers. In the case of DIDP, two different DIDPs were identified under two CAS numbers, with respective structural formulas (ECB, 2003a, 2003b).

\section{Toxicity of Selected Phthalates Other Than Reproductive Toxicity}

All investigated phthalates have low acute oral, dermal, and inhalation toxicity (IPCS, 2003; ECB, 2001, 2003a, 2003b, 2004a, 2004b; NTP-CEHR, 2003b; 2003c; OECD-HPV, 2004a), and none of them is classified for acute toxicity according to EU criteria (ECB, 2004c).

None of the phthalates investigated is classified according to EU criteria for skin, eye, or respiratory irritation (ECB, 2004c). DEHP, DIDP, and DINP showed from very slight to moderate skin irritation in experimental animals. For DEP, DnHP, and DnOP, no information on skin or eye irritation was available; for DnHP and DnOP no information on eye irritation was available. DEP, DEHP, BBP, DIDP, and DINP caused some (very slight to moderate) eye irritation in experimental animals. For DEHP and DBP the potential to cause local respiratory effects and local effects in nasal cavity and larynx, respectively, was identified-however, not to the point to trigger classification according to EU criteria. For other phthalates investigated, no information on respiratory irritation was available (IPCS, 2003; ECB, 2001, 2003a, 2003b, 2004a, 2004b; NTP-CEHR, 2003b; NTP-CEHR, 2003c; OECD-HPV, 2004a).

According to the available information, DEP, DEHP, DBP, and BBP caused no skin sensitisation in animal tests. DIDP and DINP were positive in some animal tests, but the majority of the tests were negative. The weight of the evidence does not justify classification according to EU criteria. No information on sensitisation potential was available for DnOP and DnHP. None of the phthalates investigated is classified for skin or respiratory sensitisation according the EU criteria (ECB, 2004c). Limited in vitro data indicate that DEHP due to the formation of MEHP might provoke bronchial hyperresponsiveness (IPCS, 2003; ECB, 2001, 2003a, 2003b, 2004a, 2004b; NTP-CEHR, 2003b, 2003c; OECD-HPV, 2004a).

None of the phthalates investigated is classified as mutagenic according to EU criteria. Some of the phthalates showed equivocal effects in some assays, however, they were not considered to be mutagenic (IPCS, 2003; ECB, 2001, 2003a, 2003b, 2004a, 2004b; NTP-CEHR, 2003b, 2003c; OECD-HPV, 2004a).

In repeated-dose animal studies, the liver appeared to be the target organ for all investigated phthalates. All of them showed some degree of peroxisome proliferating activity, with DEHP being the most potent. Also kidney and thyroid appeared to be the target organs for some substances, and for some, the noobserved-adverse-effect level (NOAEL) for liver and kidney damage was sometimes lower than for the reproductive effects. Male reproductive organs (testis, epididymis) were affected in repeated dose studies with DBP, BBP, and DEHP (IPCS, 2003; ECB, 2001, 2003a, 2003b, 2004a, 2004b; NTP-CEHR, 2003b, 2003c; OECD-HPV, 2004a).

None of the phthalates investigated is classified as carcinogenic according to EU criteria (ECB, 2004c). DEP showed combined incidence of hepatocellular adenomas/carcinomas in a study with mice, which is most probably related to peroxisome proliferation (IPCS, 2003). For DBP no carcinogenicity studies were available; however, in the EU Risk Assessment Report (RAR) the conclusion for this substance (also based on read-across with other phthalate esters) was that it is not carcinogenic for humans (ECB, 2004b). BBP caused peroxisome proliferation, but no hepatocellular tumors were reported; no classification for 
carcinogenicity was proposed also for this substance (ECB, 2004a). DEHP showed clear evidence of hepatocarcinogenicity in both sexes of mice and rats (attributed to peroxisome proliferating effect), increased incidence of mononuclear leukaemia in male rats, and in a lifelong study, an increase in incidence of Leydig-cell tumors. Furthermore, diffuse Leydig-cell hyperplasia was observed in young ( 3 months old) male rats in a two-generation study. Regarding

hepatocarcinogenicity, DEHP was considered not to be carcinogenic, because the mechanism of action (activation of PPARa) was not considered relevant for humans. With respect to Leydig-cell tumors, which might be relevant for humans, no conclusion concerning carcinogenic risk has been taken yet. However, no classification with respect to carcinogenicity was proposed (ECB, 2001). For DnHP and DnOP no information on carcinogenicity studies was available (NTP-CEHR, 2003b, 2003c). In carcinogenicity studies DINP induced significant increase of liver neoplasia in rat and mice; however, no classification for carcinogenicity was proposed (ECB, 2003a). No carcinogenicity studies were available for DIDP (ECB, 2003b), DiphC10 and DiC9-11 (OECD-HPV, 2004a).

\section{Reproductive Toxicity of Selected Phthalates}

To give an overview on the possible effects, a summary of information about reproductive toxicity of selected phthalates is given, which is based on summaries on reproductive effects for each phthalate investigated, given in Appendix 2. The summaries for single phthalates in Appendix 2 are listed in order based on the length of the side chains and molecular weight. The information on reproductive toxicity, if not otherwise specifically referenced, was summarised from the respective evaluation reports (see references in Table 1) for single phthalates.

The phthalates most frequently investigated with respect to reproductive endpoints are DEHP, DBP, and BBP, which together with DnHP are the ones for which clear reproductive toxic effects were observed in one or more animal species. Among all the phthalates investigated there is great variability in the number and quality of studies performed addressing reproductive toxicity. It is difficult to compare the reproductive effects observed in different studies because different protocols were used and the number and selection of endpoints investigated differ among them. Furthermore, the severity of observed toxic effects could be affected by the species and strain used, time and duration of dosing, and the dose itself. For some phthalates only studies were available in which very high dose levels were used and it was therefore not possible to identify possible reproductive effects due to severe maternal toxicity.

For phthalates, which are assumed to act as endocrine disruptors mainly by interference with male hormonal system by an antiandrogenic mechanism (Mylchreest et al., 1999; Parks et al., 2000), the time of exposure in reproductive toxicity/developmental studies is the critical factor for identification of effects on developing androgen-dependent tissues and organs. The most critical exposure time in this respect was shown to be late gestation, lactation, and through puberty, when the reproductive system is developing (ECB, 2001, 2004a, 2004b). In developmental studies of duration 6-15/16 days, these effects, or at least most of these effects were not detected (ECB, 2001, 2004a; ECB, 2004b). This is probably one of the reasons that, despite several reproductive/developmental toxicity studies on phthalates that were performed in the past 20-25 years, the antiandrogenic reproductive effects (such as reduced anogenital distance, hypospadias, nipple retention, malformed epididymis, etc.) of these substances were discovered only few years ago, when testing protocols with exposure time extended to late gestation or/and lactation were used In studies with DBP, Mylchreest et al. $(1999,2000)$ determined that the androgen-dependent sexual differentiation of male rats most probably starts at gestation day 12 and that the alterations in reproductive development and permanent disruption of reproductive function in male rats are dependent on exposure during the 10-day window (from 
gestation day 12 to 21 ) of prenatal sexual differentiation. The period most susceptible for DBP-induced undescended testis and decreased AGD in rats appears to be the period between gestation days 15 and 17 (Ema et al., 2000). On the other hand, the sensitive window for phthalate-induced abnormalities in uterine and vaginal development in rats is the time before gestation day 12 (Mylchreest et al., 1999). However, the effects observed in females are usually less severe and observed at much higher doses compared to doses at which antiandrogenic effects are seen in males (ECB, 2001, 2004a, 2004b). According to Gray et al. (2000), even by applying the studies with prolonged exposure until gestation day 19, many of the malformations in the male pups cannot be identified, as most of them are not apparent until after puberty or even later in life.

For easier understanding of the reproductive effects observed in studies with certain phthalates, the male sexual development (in particular fetal development) and the role of different hormones and cells are presented later.

Available data demonstrate that DBP, BBP, and DEHP cause severe reproductive and developmental effects in rodents. Studies were carried out also in other species, indicating that there are species differences, as some species such as the ferret or marmosets seem to be less susceptible to effects of DEHP than rats and mice. This might be in part attributed to species differences in metabolism; however, it must be pointed out that differences in study designs and timing of exposure in these studies could Iso have contributed to these differences.

In rats and/or mice, DBP, BBP and DEHP showed a similar but not identical pattern of reproductive/developmental effects, which suggests that, to some extent, different mechanisms of action are involved (Moore et al., 2001). Nevertheless, the three substances affect fertility (males and females), exert embryotoxic and teratogenic effects at doses close to or below those causing minimal maternal toxicity, and cause toxic effects to reproductive organs, predominantly in male animals, while in females the observed effects are not as severe and are usually present at higher dose levels. Furthermore, these substances appear to be more toxic and to cause irreversible effects when animals are exposed during sexual development (in utero, during lactation, or in young animals exposed before puberty). The three substances have shown to cause a series of toxic effects on androgen dependent tissues and organs in male rat offspring (such as reduced anogenital distance, hypospadias, nipple retention, malformed epididymis, etc.), which leads to the conclusion that these substances exert their effects predominantly by an antiandrogenic activity. The results of some studies with DBP and DEHP suggest that this antiandrogenic activity is not mediated by binding to the androgen receptor (AR), but rather by inhibition of testosterone production (Mylchreest et al., 1999; Parks et al., 2000; Moore et al., 2001).

Studies conducted with respective monoester metabolites indicate that it is likely that the monoester metabolites actually produce these effects (ECB, 2001, $2004 a, 2004 b)$. However, the role of other metabolites is not fully elucidated yet. For example, in the case of DEHP its metabolites 2-ethylhexanol (2-EH) and 2ethylhexanoic acid (2-EHA) might contribute to the teratogenic effects observed in animal studies (Ritter et al., 1987; Pennanen et al., 1993).

Among the selected phthalates there was another substance, DnHP, for which a continuous breeding protocol study in mice was available that showed a reduction in live pups at the lowest dose level of $380 \mathrm{mg} / \mathrm{kg}$ body weight (bw)/day. At this dose level no changes in body weight were observed. A reduction in weights of testis, epididymis, and seminiferous tubules, reduction in sperm number and motility, and changes in sperm morphology were observed at the highest dose level of $1670 \mathrm{mg} / \mathrm{kg} \mathrm{bw} /$ day (males from other dose groups were not necropsied). A crossover mating trial showed that at the highest dose levels both male fertility 
and female fertility are markedly reduced. At this dose level, systemic toxic effect such as increase in relative liver weight and kidney/adrenal weight was observed, but no histopathological changes (NTP-CEHR, 2003b). Despite the limitations of this study, the effects observed are comparable to effects observed in mice after treatment with DEHP, although DEHP appears to be more potent.

In a recent study in which effects after prenatal exposure to several phthalates on sexual differentiation of the male rats were investigated, DINP induced a significant level $(7.7 \%)$ of malformations of testis, epididymis, accessory reproductive organs and external genitalia (see Appendix 2). At this dose level no signs of maternal toxicity were observed (Gray et al., 2000). The author of this study concluded that DINP might have weak antiandrogenic activity, due to the presence of low amounts of phthalate with chain length $\mathrm{C} 6-\mathrm{C} 7$ in its mixture. In this same study, DEHP and BBP were an order of magnitude more potent than DINP, while DEP was not active at all.

DIDP showed to cause some developmental toxicity due to an observed decrease in survival indices and skeletal variations in two two-generation studies in rats, mainly in the F2 generation; however these effects were not considered severe enough to justify classification for developmental effects.

Based on the available information, other selected phthalates did not show severe reproductive effects; however, some of them showed some reproductive and/or developmental effects at very high doses and/or at doses at which there were signs of systemic/maternal toxicity.

In recent years, several studies were conducted, especially with DEHP, DBP, and $\mathrm{BBP}$, to identify the mechanism(s) of action of phthalates, in particular for effects on male reproductive organs and sexual development. However, the mechanism(s) by which these substances act are not yet fully elucidated. Some of the possible mechanisms of action, especially those related to effects similar to reproductive abnormalities observed in the human population, are briefly summarized next.

Studies show that both Sertoli and Leydig cells are targets for phthalates. It appears, however, that individual phthalate esters may exert effects on both types of cells, or one type alone (Jones et al., 1993). Due to the paracrine relationship between Sertoli cells and Leydig cells it is likely not only that the malfunction of Sertoli cells can affect the function of Leydig cells but also vice versa, leading to adverse effects in organs and tissues for which the differentiation and function depends on these two types of cells.

The results of some studies with DBP and DEHP suggest that the antiandrogenic activity is not mediated by binding to the AR receptor, but rather by inhibition of testosterone production (Mylchreest et al., 1999; Parks et al., 2000; Moore et al., 2001; Wilson et al., 2004). Both DBP and DEHP have shown to considerably reduced testosterone levels in the testis during sexual differentiation (Parks et al., 2000; Mylchreest et al., 2002). Furthermore, it was discovered, based on studies with DBP, that phthalates can affect the expression of several genes coding for proteins involved in transport of cholesterol and biosynthesis of testosterone, resulting in decreased synthesis of testosterone by the Leydig cells (Shultz et al., 2001; Barlow et al., 2003; Thompson et al., 2004). The androgens testosterone and dihydrotestosterone, which is a metabolite of testosterone, are essential for the differentiation of the male reproductive tract (Fisher, 2004). Both are produced during fetal and neonatal development. Testosterone is involved in maintenance of the Wolffian duct and differentiation into epididymis, vas deferens, and seminal vesicles, while dihydrotestosterone is involved in differentiation of the external genitalia. Therefore, the interference with testosterone production is considered to be one of the mechanisms that lead to adverse effects observed in androgen-dependent tissues and organs in rodent males, when exposed during sexual differentiation. 
In relation to interference with cholesterol transport, based on a study with MEHP, Gazouli et al. (2002) hypothesized that also the action of DEHP/MEHP as peroxisome proliferators could be involved in disturbance of cholesterol transport and reduced production of testosterone by the Leydig cells. On the other hand, the results of some other studies with DEHP show that the interaction with PPARa is not involved in testicular toxicity of this substance (Foster et al., 2001).

A third, recently discovered, hormone produced by Leydig cells, insulin-like hormone 3 (Insl3), is a peptide hormone essential for the development of male gubernaculae and trans-abdominal descent of the testis in rodents (Nef and Parada, 2000). Undescended testis induced after phthalate exposure was an effect observed in several animal studies. Wilson et al. (2004) performed a study in which DEHP, DBP, and BBP were administered to the dam (rat) from gestation day 14 to postnatal day 3 at a dose level of $750 \mathrm{mg} / \mathrm{kg}$ bw/day, to investigate the effects on steroid hormone synthesis and expression of the Insl3 gene. They discovered that the three phthalates induced alternations of InsI3 mRNA in the fetal male testis and lower levels of this hormone. Furthermore, they proposed that effects of DBP, BBP, and DEHP on InsI3 mRNA and testosterone production are a consequence of delayed maturation of Leydig cells, which proliferate which result in hyperplasia. This is often also seen in men with impaired spermatogenesis and patients with testicular cancer (Wilson et al., 2004).

\section{General Toxicity Compared to Reproductive Toxicity}

These ortho-phthalates studied in this paper show that they do not seem to be chemically reactive. Skin and eye irritation, skin sensitization, and mutagenicity are absent in most tests. Liver and reproductive toxicity are the main effects seen, indicating the importance of reproductive toxicity for this class of compound and indicating that a receptor mechanism is involved.

\section{CATEGORY APPROACH-DEFINITION OF CATEGORY}

\section{Definition of Category}

The definition in the OECD HPVC manual says, "A chemical category is a group of chemicals whose physicochemical and toxicological properties are likely to be similar of follow a regular pattern as a result of structural similarity. These similarities may create a predictable pattern in any of the following properties; environmental fate, environmental effects and human health effects. The similarities can be based on a common functional group...; or the likelihood of common precursors or breakdown products...; and an incremental and constant change across the category." Therefore this definition of category will start with the commonly available physicochemical properties and the data available on metabolism, and ends with similarities in reproductive toxicity.

Molecular weights of the substances range from approximately 222 for DEP to approximately 447 for DIDP and DiC9-11. All of them have low water solubility, with the highest being for DEP $(1 \mathrm{~g} / \mathrm{L})$, and there is a decrease in water solubility with increasing length of the side chain and molecular weight. The log $K_{\text {ow }}$ is around 2.5 for DEP; for all other substances the log $K_{\text {ow }}$ is higher than 4 and onward from DnHP, larger than 6.

Oral absorption is relatively high for all the substances, but appears to be saturable for phthalates with side chains of C6 or longer. It is assumed, because of the rapid hydrolysis process after oral ingestion, that these substances are mainly absorbed as monoester derivatives rather than as diesters.

It appears that for all the investigated substances the first step in systemic metabolism of any absorbed diester is rapid hydrolysis to monoester, which can be then followed by further hydrolysis and/or oxidation and glucuronidation. All of 
the substances are considered to be eliminated from the organism in few days, and none of them is considered to accumulate in the organism.

When considering the physicochemical properties of the selected phthalates, it appears that they do not play an important role in reproductive toxicity as there appears to be no straightforward trend and "cutoff" value from which to derive a conclusion on why certain phthalates do and others do not cause reproductive toxicity. Despite high log $K_{\mathrm{ow}}$ values and low water solubilities, the phthalates absorb well and are metabolized (Appendix 1 ). This can be explained by the potential metabolisation in the gut, decreasing log $K_{\text {ow }}$ and increasing water solubility, and increasing absorption of the monoesters. Though the orthophthalates have a similar pathway of breaking down, the metabolites follow the same pattern as the parent compounds, which are according to differences in Cbackbone lengths. Therefore, the category has to be defined on a similar mechanism, which we mostly had to interpret as similarities in reproductive effects.

Another difficulty when assessing the phthalate toxicity in a regulatory framework is that the effects are not that obvious in the 28-day studies and developmental toxicity studies. It is now known that females need to be exposed in the most critical period of 12-21 days during pregnancy to see testicular effects at low doses ( $<10 \mathrm{mg} / \mathrm{kg}$ bw for DEHP). Therefore only in a one-or two-generation study the most critical effects are seen. In the required regulatory developmental study (OECD 414) the exposure stops at 15 days of gestation. Testis effects are seen in 28/90-day studies but generally at higher doses or depending on the details of the histopathology on the testis. In the one-generation studies these testis effect are pronounced, but then this also depends on the details of the histophathology.

This review shows that the reproductive toxicity tests and effects have to be available in this detail to show this specific mechanism. Knowing this specific mechanism, other phthalates can be tested with a focus on specific effect to see whether they show a similar mechanism. In view of this specific similar mechanism of the phthalates tested, it also is expected that that the effects of the phthalates are additive, which is also indicated by DiGangi (2002).

From a regulatory perspective, effects of chemicals need to be assessed for different frameworks, that is, for hazard assessment, classification and labeling, PBT (persistent, bioaccumulating, and toxicity) assessment, and risk characterization (indicating a level of concern when relating exposure with effect data). A hazard can be assessed with a derived N(L)OAEL, which is also used in the risk characterisation. For classification and labeling purposes the reproductive effects need to have a certain severity below $1000 \mathrm{mg} / \mathrm{kg}$ bw, which cannot be explained by maternal toxicity and will only be assessed dependent on the availability of data. The reproductive effects observed with the phthalates outside the boundaries of $\mathrm{C} 4-\mathrm{C} 6$ backbone show similarities with the C4-C6 group. These effects have not yet been assessed in sufficient detail in the EU classification and labeling group, or were above the $1000 \mathrm{mg} / \mathrm{kg}$ bw level, were less severe or have not yet been tested adequately considering measuring effects. Therefore it is important to distinguish between hazards as such and the needs for classification and labeling, especially when considering additive effects. A summary of the reproductive effects of the phthalates is given in Appendix 2.

In Appendix 2, from the phthalates selected, DEHP (C6 backbone, branched, 2 identical chains), DBP (C4 backbone, straight, two identical chains), and BBP (C4 backbone, straight, nonidentical chains) cause significant reproductive effects in rodents, such as reduction of fertility of both sexes, effects on reproductive organs (particularly in males, and more pronounced if exposure occurred during sexual development), and teratogenic effects. DEHP appears to be the most potent of them. The most critical effects are effects on male reproductive organs. The type of effects they produce, especially in developing male reproductive 
organs, and the absence of clear estrogenic effects for in vivo studies (DBP and BBP exhibited weak estrogen receptor [ER]-mediated estrogenic activity in some in vitro studies), lead to the conclusion that all three substances act mainly by an antiandrogenic mechanism. DEHP, DBP, and BBP are classified as reproductive toxicants according to EU criteria for fertility and developmental effects. However, DnHP ( 2 identical unbranched C6 chains), for which only very limited information was available, also seems to be able to produce effects in mice (reduced fertility of both sexes and embryolethality) similar to those observed with DEHP.

Unfortunately, in the study with DnHP only high-dose males were necropsied, and therefore it was not possible to determine whether effects on male reproductive organs also occurred at lower dose levels.

In a recent study, DINP also induced a significant level of malformations in male reproductive organs, indicative of an antiandrogenic mechanism, and, according to the author of the study, the effects occurred due to the presence of some phthalates with C6-C7 ester group in ortho position in the mixture (Gray et al., 2000).

For other selected phthalates, although some reproductive effects were seen in some studies, these were observed only at high doses or they were not considered severe enough to classify them as reproductive toxicants. DINP, DIBP, $\mathrm{Di}-\mathrm{phC10}$, and Di-C9-11 have recently been assigned to the category of highmolecular-weight phthalate esters in the OECD-HPV chemicals program, and were not considered to be reproductive toxicants (OECD-HPV, 2004a). However, whether this is justified, based on a more detailed description of the effects in this review, needs further research and is illustrated with some examples.

In most repeated-dose studies the testicular effects were looked at but the level of detail differs in the studies available. The testis weights in a 13-week study were affected at $5000 \mathrm{ppm}(375 \mathrm{mg} / \mathrm{kg} \mathrm{bw})$ but not at lower doses. The testis weights of rats after exposure of DEHP were affected at 20000 ppm (N1156 $\mathrm{mg} / \mathrm{kg} \mathrm{bw}$ ), and from $5000 \mathrm{ppm}$ (284 mg/kg bw) onward, while for Di-phC10 (C7 backbone and propyl chain) no testis or epididymides weights changes were observed (IUCLID data set) at 15,000 ppm $(1000 \mathrm{mg} / \mathrm{kg} \mathrm{bw})$. These data show that testis weight is not a very sensitive parameter for the reproductive toxicity of phthalates. The age of the animals when starting exposure is important, as older rats are less susceptible to effects than younger ones. The age of the rats at the start of exposure is not always clear in these repeated-dose studies. The age of the rats was reported as 6 weeks in a 104-week diet study. In this study the testis weight effects were seen at $292 \mathrm{mg} / \mathrm{kg}$ bw but not at lower doses. The start of exposure is less clear in shorter diet studies and may have been performed with older rats, and the effect might have been missed in the Di-phC10 study. In view of the small differences in structure, it is expected that Di-phC10 would have some similar testicular toxicity.

Two continuous breeding studies in mice for DEHP (C6 backbone) and DIDP (C8 backbone) showed effects on testis and related organs at $600 \mathrm{mg} / \mathrm{kg}$ bw for DEHP, while for DIDP the relative seminal vesicles weight was decreased at 7500 $\mathrm{mg} / \mathrm{kg}$ feed, $\mathrm{N} 350 \mathrm{mg} / \mathrm{kg}$ bw.

Two other type of effects can be noted at $<1000 \mathrm{mg} / \mathrm{kg} \mathrm{bw} /$ day. First is the significant level of malformation at $750 \mathrm{mg} / \mathrm{kg}$ bw of DINP (C6-9 backbone) (exposure from gravid day 14 to postnatal 3), which can be compared with testicular effects of gestational and lactational exposure to DEHP also at dose levels of $750 \mathrm{mg} / \mathrm{kg}$ bw/day.

Second, in the developmental studies (all with extended exposure during gestation), for Di-phC10 (C7 backbone), slight but significant skeletal and total variations were increased at $1000 \mathrm{mg} / \mathrm{kg} \mathrm{bw}$, similar to DEHP (C6 backbone) at $750 \mathrm{mg} / \mathrm{kg}$ bw as well as to Di-C9-11 (C8-10 backbone), which showed minor skeletal and visceral variations at $1000 \mathrm{mg} / \mathrm{kg}$ bw. 
The similarities in effects of the different phthalates have to be reviewed in detail as shown with the preceding examples, because of different exposures (feed and gavage) and exposure duration and most importantly whether the authors looked at specifically at testicular toxicity. Also from this review the difference in susceptibility in mice and rats and other animals is not as clear, because of various differences in test methodology and effects that are looked at, despite the observation of the World Health Organization (WHO) that rats may be more susceptible than mice for DEHP (WHO/IPS, 1992).

Based on information on physicochemical properties, structural similarities (orthophthalates with alkyl side chains, linear or branched, of length C4-C6), similarities in oral absorption values and metabolism, and the fact that for three of them there is a large amount of data on reproductive toxicity, which indicate that they exert similar adverse effects on reproduction, a category for DBP, BBP, and DEHP (category for ortho-phthalates with alkyl side chains length from C4 to C6) for reproductive effects (including effects on reproductive organs, fertility, and development) could be defined. Due to the structural similarities and indications from (limited) studies that this substance can induce severe reproductive effects (which to some extent are similar to those produced by DEHP), it is proposed to include also DnHP in this category by applying the readacross.

To further evaluate and determine the domain of the proposed category, information was collected also on dipropyl phthalate (DPrP, side-chain length C3, straight, two identical chains); Din-pentyl phthalate (DPP), side-chain length C5, straight, two identical chains; and diisoheptyl phthalate (DIHP, mixture, sidechain lengths from $\mathrm{C} 6$ to $\mathrm{C} 8$, predominantly $\mathrm{C} 6$, with various branching) (Table 2). 
Critical Reviews in Toxicology, 36:695-726, 2006

TABLE 2 Phthalates for evaluation and determination of the domain of the category

Dipropyl phthalate-DPrP

(CAS: 131-16-8)



Di-n-pentyl phthalate-DPP

(CAS: 131-18-0)



Di-isoheptyl phthalate-DIHP

(CAS: 71888-89-6)



Di-allyl phthalate-DAP

(CAS 131-17-9)



Di-ethylhexyl terephthalate-DEHT

(CAS: 6422-86-2)




The effects of DPP and DPrP on testis and zinc metabolism were studied in rats by Foster et al. (1980). His intention was to compare the effects of these two substances with effects observed after treatment with $2000 \mathrm{mg} / \mathrm{kg}$ bw/day DBP in a previous study. Groups of young male rats were orally exposed for four days to a dose of approximately $2100 \mathrm{mg} / \mathrm{kg}$ bw/day of DPP and of approximately 1800 $\mathrm{mg} / \mathrm{kg} / \mathrm{bw}$ of DPrP. According to Foster et al., DPP caused exactly the same effects as DBP: severe atrophy of the seminiferous tubules, with a complete loss of spermatocytes and spermatides in the majority of them; only a few spermatogonia and Sertoli cells remained attached to the basement membrane. Furthermore, an increase in urinary excretion and reduction in content of zinc in the testes was observed. No changes in interstitial cells were observed. No effects were observed in the males treated with DPrP. At these dose levels no changes in food consumption or weight gain were observed. In this same study, dimethyl phthalate (DMP), DEP, DnHP, Din-heptyl phthalate (DHeP), and DnOP were also investigated. Only DnHP showed the same effects as DPP, but at a higher dose level, $2400 \mathrm{mg} / \mathrm{kg}$ bw/day (the only dose tested). Other phthalate esters did not produce any effects on testis or on testicular zinc content.

DPP was also studied in a continuous breeding protocol study with mice (Heindel et al., 1989). The animals were exposed to $0.5,1.25$, and $2.50 \%$ DPP in the feed, corresponding to approximately 480,760 , and $2160 \mathrm{mg} / \mathrm{kg}$ bw/day. Only 4 out of 19 pairs in the low-dose group delivered a litter, while no litters were produced in the middle-and the high-dose groups. A cross-mating trial between high-dose and low-dose animals showed that fertility was affected in both males and females. Only the control and high-dose animals were necropsied. At this dose level, body weight in both sexes was significantly reduced and relative liver weight was significantly increased. In males, reduced weight of seminal vesicles and epididymis was observed, a $78 \%$ reduction in absolute testis weight, and there were no detectable epididymal sperm.

In the same type of study, DPrP did no show any adverse reproductive effects at a dose level of $1900 \mathrm{mg} / \mathrm{kg}$ (Heindel et al., 1989).

Based on the information in the draft OECD SIAR and SIAP (SIDS Initial Assessment Report Profile) for DIHP (OECD-HPV, 2004b, 2004d), this is a substance for which the side-chain lengths can vary from C6 to C8 (mainly C6), with various branching patterns. The structural formula in Table 3 was derived by the EPIWin1.3 program. 
TABLE 3 Structures of the monoester side chains of different isomers of MBuP

Mono-n-butyl phthalate

iso-Butyl phthalate

sec-Butyl phthalate

tert-Butyl phthalate


In relation to the fact that this substance contains phthalates with $\mathrm{C} 6$ side chains, it was expected that some reproductive toxicity similar to that observed with other "C4-C6" phthalates would be observed. In fact, in a two-generation study with rats, effects such as decreased reproductive performance in the F1 generation were observed in both sexes at a concentration of $8000 \mathrm{ppm}$ in the diet [the highest dose tested, corresponding to approximately $760 \mathrm{mg} / \mathrm{kg}$ bw/day (males) and $830 \mathrm{mg} / \mathrm{kg}$ bw/day (females)]. At these dose level, decreased mean sperm production and decreased testicular sperm concentration were also observed. Developmental effects in the F1 generation were reduced anogenital distance, delay in balanopreputial separation, testicular abnormalities, changes in external genitalia, and retention of thoracic nipples. These effects were predominantly seen at $8000 \mathrm{ppm}$. In the F2 generation similar effects were seen, in some cases at a significant level, already at $4500 \mathrm{ppm}$ (corresponding to a dose around $300 \mathrm{mg} / \mathrm{kg}$ bw/day for dams during gestation and $750 \mathrm{mg} / \mathrm{kg}$ bw/day during lactation). Systemic effects such as increased liver and kidney weights and pituitary weights (only F1 males) were observed at 4500 and 8000 ppm. The NOAEL for parental systemic effects in the F0 and F1 generation was set to $1000 \mathrm{ppm}$ (range from 64 to $168 \mathrm{mg} / \mathrm{kg} \mathrm{bw} / \mathrm{day}$ ); the same NOAEL was also set for reproductive effects (range 64 to $168 \mathrm{mg} / \mathrm{kg}$ bw/day during gestation and lactation period). Furthermore, this substance was also tested in a developmental study with rats, with exposure from gestation day 6 to 20. In this study an increase in resorptions, a decrease in live fetuses, and an increase of fetuses with external, visceral, and skeletal malformations were observed at the two highest dose levels of 300 and $750 \mathrm{mg} / \mathrm{kg}$ bw/day. At these dose levels there was an increase in liver weights. No information is given on whether an examination on reproductive organs of male pups was performed. The NOAEL for developmental effects was set to $300 \mathrm{mg} / \mathrm{kg}$ bw/day, while the NOAEL for maternal effects was $750 \mathrm{mg} / \mathrm{kg}$ bw/day. 
The available information for DPP and DIHP is in line with the assumption that alkyl phthalates with side-chain lengths of $\mathrm{C} 4-\mathrm{C} 6$ produce severe reproductive toxicity and therefore that DPP and DIHP could also be included in the "C4-C6 category."

To further determine the boundaries of the proposed category, information about an ortho-phthalate with a double bond in the side chains, diallyl phthalate (DAP), was checked (Table 3 ).

According to the information that was available for the preparation of the SIAP under the OECD-HPV program (OECD-HPV, 2004c), this substance did not affect male or female fertility, offspring viability, or growth and development from conception to early lactation in a reproduction/developmental toxicity screening test with rats and did not induce any abnormalities in offspring exposed prenatally and postnatally. However, in the $150 \mathrm{mg} / \mathrm{kg}$ bw/day group (the highest dose tested), three females showed signs that were attributed to possible dystocia. The effects on newborns and live newborns from these females were not evaluated. The NOAEL for general and reproductive/developmental toxicity was set to $50 \mathrm{mg} / \mathrm{kg}$ bw/day (the next lower dose tested). The same NOAEL was set for general (systemic) toxicity. DAP is also acutely toxic, sensitizing, might be mutagenic, and there is equivocal evidence of carcinogenicity in female rats. It appears that this substance differs considerably from the four phthalates producing reproductive effects, in terms of both general toxicological effects and reproductive effects. Furthermore, it differs also from other phthalates investigated. The difference in toxicity pattern compared to other phthalates investigated is not surprising, since the double bond in the side chains gives possibilities of metabolism different from the saturated side chains.

In order to determine whether the position of the ester influences the toxicity of phthalates, data concerning two studies on phthalates with esters on positions other than ortho were looked at.

In the study of Gray et al. (2000) in which several phthalates were investigated for effects on development of male reproductive tract after perinatal exposure (gestation day 14-postnatal day 3), DEHT, a phthalate ester with C6 side chains in para position (Table 3 ), did not induce any malformations of the reproductive tract, while DEHP and BBP produced severe malformation and DIDP slight. Moreover, the conclusion of the OECD SIAP (OECD-HPV, 2003) for this substance also was that it has low potential to induce reproductive toxicity.

Furthermore, Foster et al. (1982) observed that when young male rats were treated with di- $n$-butyl esters of iso- and tere-phthalic acid, no effects on testes were observed, while when treated with di- $n$-butyl esters of ortho-phthalic acid, severe testicular atrophy and altered zinc metabolism was observed. This could be an indication that phthalates with side chains of length $\mathrm{C} 4-\mathrm{C} 6$ in positions other than ortho are not reproductive toxicants, or at least not in the same way as ortho-phthalates. However, to conclude this with certainty, further investigation would be needed.

From the analysis performed, it appears very likely that phthalates with the ester bound in ortho position and alkyl side-chains length from C4 to C6 will produce severe reproductive effects, including effects on fertility, male reproductive organs, and developmental effects other than effects on reproductive organs. In this respect, care should also be taken when dealing with phthalates that are mixtures of phthalates with different side chain lengths. As it was shown in the case of DINP and DIHP, these could also produce similar effects when containing phthalates with shorter side chains (from C4 to C6) in the mixture. In fact, it appears that the amount of phthalates with shorter side chains in the mixture is 
probably the factor that will determine whether the mixture will have significant reproductive effects or not. Therefore, when assessing such mixtures it is not enough to determine the predominant side-chain length, or the different chain lengths, but also the amount, especially, of the shorter side chains (e.g., C4-C6) in the mixture.

Concerning the ortho-phthalates with backbone equal to or lower than C3, it seems less likely that they would produce severe reproductive effects similar to those observed in DBP, BBP, and DEHP at low doses, but there are indications that at very high doses these could be observed. Concerning the ortho-phthalates with backbone equal or higher than $\mathrm{C} 7$, more research and testing might be needed to in-or exclude them.

For phthalates with side-chain lengths equal to or shorter than 3 , there is another uncertainty. In the study with isomers of MBuP (Table 3)-mono- $n$, iso-, sec-, and tert-butyl phthalate-marked testicular atrophy and altered zinc metabolism were observed with mono- $n$-butyl, mono-iso-butyl, and mono-sec-butyl isomers, while the mono-tert-butyl isomer did not produce any effects (Foster et al., 1981, 1982). Therefore, it is possible that, for example, a phthalate ester with branched side chain of $\mathrm{C} 3$ length could also produce reproductive effects. In this case, the lower boundary of the category would not be the side-chain length $\mathrm{C} 4$, but rather the number of $C$ atoms in the longest branch of the side chains, which should be at least 3 . However, to conclude this, further investigation would be needed.

\section{Definition of the Structural Alert}

Based on all the phthalate esters investigated, a structural alert applicable to the "C4-C6 phthalate" category for phthalates causing severe reproductive toxicity that likely need classification and labeling for reproductive effects is proposed (Figure 3). For somewhat smaller and longer alkyl chains, reproductive effects are expected; the necessity for classification and labeling needs further research.





$\mathrm{R} 1$ and/or $\mathrm{R} 2=$
FIG. 3 Structural alert for orthophthalates causing severe reproductive toxic effects that may need classification.

\section{CONCLUSION}

In the European Union, legislation concerning risk assessment and management of "industrial chemicals"-new and existing chemicals-has existed already for more than a decade. However, because of the very complicated and timeconsuming processes in assessing the risks, especially of existing chemicals, there is still a large number of chemicals for which the possible risks for human health and the environment have not yet been assessed. It is believed that for most of these chemicals, basic data for the assessment is lacking. The new chemicals policy (REACH) that has recently been proposed is expected to considerably speed up this process. However, this will indubitably among other things require the generation of a huge amount of data on hazardous properties of chemicals, inevitably also by conducting animal tests. Reproductive toxicity is one of the most complicated, time-consuming, and expensive endpoints to assess 
experimentally, for which the highest number of experimental animals is needed as compared to other toxicology subdisciplines. However, by developing valid alternative methods to animal testing, at least in some cases such tests may be avoided in the future.

In this article, the applicability of the category approach for reproductive toxicity endpoints was investigated, using phthalates as example. By selecting a group of 10 ortho-phthalate esters, the intention was to identify the similarities and differences between these substances, determine which substances produce reproductive effects and which not, and whether there is a "common factor" that differentiates the phthalates that produce reproductive effects in experimental animals from those that do not.

It seems that there are no great differences in physicochemical properties, absorption rates, and metabolism between the phthalates investigated that could fully explain the difference in reproductive toxicity. Based on the available information, it was concluded that DBP, BBP, and DEHP, alkyl phthalates with side-chain length of $\mathrm{C} 4-\mathrm{C} 6$, produce similar severe reproductive effects in experimental animals: (1) They reduce fertility in both sexes, (2) they adversely affect predominantly sexual development of male animals, and (3) they produce also developmental effects other than effects on reproductive organs at dose levels below or at which slight maternal toxicity is observed. Effects on sexual development of males appear to be the most critical effects for all three substances. Furthermore, studies show that the monoester metabolites are largely responsible for reproductive effects, and that they most probably share a similar mechanism of action related to antiandrogenic activity. These features differentiate the three phthalates just mentioned from the others among the 10 phthalates investigated, except for DnHP (side chains length C6), which, although very limited data on its reproductive toxicity are available, to some extent shows similar effects in rodents as DEHP. It is proposed that based on the reproductive effects produced by DBP, BBP, and DEHP, a category be established for the dialkyl phthalates with side-chain length $\mathrm{C} 4-\mathrm{C} 6$, also including DnHP in this category. In addition, DPP and DIHP were also found to possess similar properties, suggesting that they could be suitable candidates for this category, too. Based on all the phthalate esters investigated, a structural alert for phthalates causing severe reproductive toxicity that would indicate a need for classification and labeling for reproductive effects (fertility and developmental) was proposed.

The "commonly accepted" assumption, introduced by Foster et al. (1982), has now been defined in more detail: The C4-C6 backbone (i.e., the length of the longest branch in the side chain) is probably more important than the total number of $\mathrm{C}$ atoms in the chain. Shorter and longer $\mathrm{C}$ backbones may need further evaluation before definite conclusions can be drawn on their properties with respect to reproductive toxicity. The antiandrogenic effects seem relevant for most of the phthalates that were discussed. In this investigation it was shown that special attention should be posed to complex mixtures of phthalates, especially those that contain also phthalates with shorter chains (C4-C6). It is assumed (and this was also shown in the case of DIHP) that complex mixtures that contain considerable amounts of phthalates with side-chain lengths C4-C6 will cause severe reproductive effects similar to those of other "C4-C6 phthalates." Therefore, depending on the content of the short-chain phthalates in the mixture, they should also be considered for the "C4-C6" category and eventually also for classification and labeling. For this later purpose, the application of the criteria from the "EU Preparation Directive" 1999/45/EC could be considered.

It is expected that phthalates included in the tight boundaries of the proposed category would all show reproductive effects, especially the antiandrogenic effects, and very likely classification and labeling may be needed for all of them. 
Further testing might not be necessary for phthalates within these boundaries. If necessary, testing could focus on critical endpoints. However, this does not imply that phthalates outside this domain do not show any reproductive toxicity. In fact, it was observed that phthalates with shorter and longer side chains could also produce some less severe reproductive effects or effects at higher doses.

Since there are strong indications that the substances within the boundaries of the proposed category produce similar reproductive effects and at least in part share the same mechanism of action in terms of reproductive toxicity, consideration of the aggregate exposure to these substances should be taken into account. This was suggested also by DiGangi et al. (2002).

To conclude, the category approach can be applied for reproductive endpoints. One critical requirement for the success of this approach is the availability of a toxicity database that is elaborate enough to base conclusions on. However, the goal for which the category approach is intended to be used (classification and labelling, risk assessment, grouping of anti-androgenic endocrine disruptors, etc.) should be clear beforehand, in order to be able to define the domain. This investigation showed that for the derivation of the category a trend of increasing/decreasing toxicity could not be automatically assumed only based on increasing/decreasing trend in physicochemical properties or molecular weight. Furthermore, it also shows that the length of certain parts (chains) of a substance's structure could be more important than the number of atoms present. It is very important when applying the category approach that at least some information on metabolism and mechanism(s) of action of substances based on which the category is defined be available, in order to have some certainty in deciding which substance is to be a member of the category and which not. In this case, a relatively rough assessment of fertility and developmental effects was performed. From this assessment it was concluded that the effects on male sexual development (effects related to the antiandrogenic activity) appeared to be the most critical and the definition of category was mostly based on this. A more detailed analysis of all the effects and an assessment on how these effects cluster with structural and physicochemical properties would increase the strength of the category approach.

\section{APPENDIX 1}

The selected phthalates are listed in the table, with the respective diester structural formulas and of their monoester metabolites. The order of the list is based on the length of side chains and molecular weight. Furthermore, information on physicochemical properties, oral absorption, and metabolism after oral absorption is given. Structural formulas of diesters were drawn based on the structural formulas derived with the EPIWIN 1.13 program. The information listed in the table was, if not otherwise referenced, summarized from the respective evaluation reports of single phthalates listed in Table 1.

\section{APPENDIX 2}

The information given in the summaries on reproductive toxicity for the selected phthalates, if not otherwise specifically referenced, was summarized from the respective evaluation reports (see Table 1 ) for single phthalates.

\section{DEP (Diethyl Phthalate, C2 Backbone)}

\section{Effects on Fertility and Reproductive Organs}

In the few studies available where rats and mice were exposed to DEP, some effects on male reproductive organs were observed only at very high doses $(32000 \mathrm{mg} / \mathrm{kg} \mathrm{bw})$. Treatment of rats with $2 \%$ DEP in the diet $(2000 \mathrm{mg} / \mathrm{kg}$ bw/day) for 1 week decreased testosterone concentration in testes 
and serum (approximately 40\%). In rats, ultrastructural changes in Leydig cells were observed at oral doses of $2000 \mathrm{mg} / \mathrm{kg}$ bw/day for 2 days.

In a continuous breeding study with mice, no effects were observed in the $F_{0}$ generation following dietary administration of $3640 \mathrm{mg} / \mathrm{kg}$ bw/day. Decreased epidydimal sperm concentration of the F1 generation and decreased number of live $F_{2}$ pups together with mild inhibition of body weight gain and moderate increase in liver and prostate weights were observed at the same dose.

Based on available data, DEP has no adverse effects on fertility of females.

\section{Developmental Effects Other Than Effects on Reproductive Organs}

No developmental/teratogenic effects were observed in a teratogenicity study with rats exposed to concentrations of DEP in the feed up to $5 \%(3200 \mathrm{mg} / \mathrm{kg}$ bw/day) and in a preliminary developmental toxicity study in mice dosed $4500 \mathrm{mg} / \mathrm{kg}$ bw/day by gavage.

Considering species, sensitive exposure period, and specific antiandrogenic effects, it can be seen in the preceding summary that species differences are difficult to judge as mostly within these studies different reproductive endpoints were looked at. In the continuous breeding study with mice the critical period for showing antiandrogenic effects was covered.

\section{DBP (Dibutyl Phthalate, C4 Backbone)}

DBP is classified according to EU criteria as reproductive toxicant: Repro cat. 2: R61-May cause harm to the unborn child, and R62-Possible risk of impaired fertility (ECB, 2004c).

\section{Effects on Reproductive Organs and Fertility}

Mice Male fertility in mice did not appear to be affected in a one-generation study by the highest dose level tested of $1.0 \%$ in the diet (equivalent to $1410 \mathrm{mg} / \mathrm{kg}$ bw/day), while female fertility was clearly affected (statistically significant decreases in percentage of fertile pairs, number of litters/pair, number of live pups/litter and proportion of pups born alive was observed). The NOAEL for parental toxicity and embryotoxicity was $0.3 \%$ ( $\square 420 \mathrm{mg} / \mathrm{kg}$ bw/day).

Rats In studies with rats, exposure of animals after weaning caused delayed puberty in males and reduced fertility in both males and females. Infertility in males was attributed to testicular atrophy and reduced sperm production, while females cycled and mated successfully, but many of the treated females aborted their litters around mid-pregnancy. Embryotoxicity was observed at dose levels, which did not produce any maternal toxicity. The lowest LOAEL for embryotoxicity was set to be 52 $\mathrm{mg} / \mathrm{kg}$ bw.

In males that were exposed in utero and during lactation, urogenital malformations/abnormalities were mainly observed from dose levels of $250 \mathrm{mg} / \mathrm{kg}$ bw/day up. The observed effects were hypospadias, ectopic testis, renal agenesis, increased incidence of dilated renal pelvis, reduced epididymal sperm count, reduced testicular spermatid head counts, absent or poorly developed epididymis, atrophy of seminiferous tubules, tesicular atrophy, poorly developed seminal vesicles, underdeveloped prepuce or penis, delayed preputial separation (observed already at $100 \mathrm{mg} / \mathrm{kg}$ bw/day), abnormal or reduced spermatogenesis, retained thoracic nipples, and decreased AGD (observed already at $100 \mathrm{mg} / \mathrm{kg}$ bw/day). At dose level of $500 \mathrm{mg} / \mathrm{kg} \mathrm{bw} /$ day, the effects observed were hypospadias, cryptoorchidism, agenesis of the prostate, epididymis, vas deferens, penis malformations, areolae (observed already at $100 \mathrm{mg} / \mathrm{kg}$ bw/day), and formation of large aggregates of Leydig cells. In a continuous breeding study, the animals exposed in utero and during lactation showed also reduced fecundity. Maternal toxicity in these studies was observed from dose level 500 $\mathrm{mg} / \mathrm{kg}$ bw/day on. A NOAEL could not be derived from the available development studies in rats.

Barlow et al. (2004) diagnosed testicular dysgenesis, a lesion of proliferating LCs and aberrant tubules, in male pups in one of the studies after in utero exposure of dams to $500 \mathrm{mg} / \mathrm{kg}$ bw/day DBP during late gestation (GD12-21). He suggested that testicular dysgenesis was formed in utero while the differentiating testes were being exposed to DBP and continued to develop as rats were growing older.

Rats showed characteristic testicular changes after repeated oral exposure to DBP. The lowest tested dose of $250 \mathrm{mg} / \mathrm{kg}$ bw/day induced already changes in testicular enzymes associated with degeneration of spermatogenic cells, and histopathology showed some testicular degeneration at this dose level. At dose levels of $500 \mathrm{mg} / \mathrm{kg} \mathrm{bw} /$ day and higher, decreases in weight of testes (atrophy) and accessory sex glands, decreased numbers of spermatocytes, degeneration of seminiferous tubules of the testes, a reduction in testicular zinc levels and serum testosterone levels, increases in testosterone levels in testes, and an increase in urinary zinc excretion were observed.

In female rats exposed in utero and during lactation at $250 \mathrm{mg} / \mathrm{kg} \mathrm{bw}$, sporadic cases of renal agenesis and uterine abnormalities (partial agenesis or lack implants in one uterine horn) and reduced fecundity under continuous breeding conditions were found.

In a study of prepubertal development in rats exposed in utero (dams were exposed in feed at doses approximately $12 \mathrm{mg} / \mathrm{kg}$ bw/day and $50 \mathrm{mg} / \mathrm{kg}$ bw/day), body weight gain of the highest dose dams was reduced. Female pups presented an evident, statistically significant delay in their vaginal opening ( 2 days) at both dose levels and a statistically significant delay in occurrence of first estrus ( 2 days) in the highest dose group (Salazar et al., 2004). 
K. Lee et al. (2004) studied developmental toxicity of DBP in rats, exposing dams from the period of late gestation to following lactation. A LOAEL of $20 \mathrm{ppm}(1.5-3.0 \mathrm{mg} / \mathrm{kg}$ bw/day) in maternal diet was set in a study, based on persistent mammary gland toxicity (degeneration and atrophy of mammarygland alveoli) in males.

Rabbit In a recent study in the rabbit exposed in utero, during adolescence, or after puberty to 400 $\mathrm{mg} / \mathrm{kg}$ bw/day, DBP caused developmental and/or reproductive toxicity. The most pronounced effects were observed in rabbits exposed in utero. In rabbits exposed to DBP (from GD 15 to 29),

cryptorchidism, malformations of reproductive organs, decreased weights of the testes and accessory glands, and deteriorated seminal parameters were observed. Independently of the window of exposure, a lower number of morphologically normal sperm in the ejaculates was observed and increased germinal epithelial loss. Furthermore, exposure to DBP in utero or during adolescence decreased the number of sperms in ejaculate. In one rabbit exposed in utero and during adolescence, atypical germ cells resembling carcinoma in situ (CIS) in undescended testis were observed. In the current study, in utero or adolescent exposure to DBP decreased concentrations of testosterone at 6 weeks.

Also in guinea pigs severe testicular changes were observed after repeated oral administration, while mice and hamsters appeared to be less sensitive to testicular effects. The species difference in severity of testicular toxicity may be due to differences in concentrations of free MBuP.

\section{Developmental Effects Other Than Effects on Reproductive Organs}

In a study with mice, embryotoxicity (lower number of live offspring) and teratogenic effects were observed at the highest dose level tested $(400 \mathrm{mg} / \mathrm{kg} \mathrm{bw})$. The teratogenic effects observed were statistically significantly higher incidence of external anomalies (non-closing eyelid), encephalocele, cleft palate, and spina bifida. Slight maternal toxicity (increased kidney weights) was observed at the same dose level. The NOAEL for maternal toxicity, embryotoxicity, and teratogenicity in this study was $100 \mathrm{mg} / \mathrm{kg}$ bw/day.

In studies with rats, effects such as a statistically significant postimplantation loss (from dose 630 $\mathrm{mg} / \mathrm{kg}$ bw on) and a significant increase number of external and skeletal malformations (from dose $750 \mathrm{mg} / \mathrm{kg}$ bw on) were observed. However, the relevance of these effects was considered questionable, as maternal toxic effects in studies with rats were observed from dose $500 \mathrm{mg} / \mathrm{kg} \mathrm{bw}$ on.

\section{Information on Possible Mechanisms of Action}

In studies with the metabolite MBuP, it caused developmental toxicity similar to that of DBP, and these effects were produced at approximately equimolar concentrations, which strengthens the hypothesis that the metabolite MBuP is responsible for developmental effects of DBP.

Foster et al. $(1981,1982)$ studied the structure-activity requirements for the induction of testicular atrophy by butyl phthalates. He exposed young male rats by gavage to $800 \mathrm{mg} / \mathrm{kg}$ bw/day of isomers of mono-butyl-ortho-phthalate: mono- $n$, iso-, sec-, and tert-butyl ortho-phthalate. All animals, except those treated with mono-tert-butyl ester developed marked testicular atrophy; zinc metabolism was also affected. Furthermore, in a different experiment, Foster dosed male rats with equimolar doses of di- $n$-butyl esters of ortho, iso-, and tere-phthalic acids. Only the ester with ortho position produced damage to the testis and affected the metabolism of zinc. From these studies he concluded that the esters need to be of specific chain length and in the ortho position in order to cause testicular atrophy. Studies with the monoester metabolite MBuP show that MBuP is toxic to the male reproductive tract, which supports the role of MBuP in mediating toxicity to the male reproductive tract (NTP-CERHR, 2003a).

In some special in vitro assays, DBP showed weak estrogenic activity, but estrogenic effects were not confirmed during in vivo studies. However, in the study of pre-pubertal development of rats exposed in utero to DBP (Salazar et al., 2004), the effects on development of female pups from dams exposed to DBP might suggest that DBP possesses some estrogenic activity. Furthermore, the authors of a study on dose-dependent effect of phthalate ester (MBuP) on testicular descent in pre-and postnatal rats hypothesized, that high doses of MBuP inhibit the transabdominal descent of the testes, probably due to its estrogenic activity, whereas low doses of MBuP may act as an antiandrogen and thereby inhibit inguinoscrotal testicular descent in postnatal rats (Shono and Suita, 2003).

Results of developmental studies are indicative of an antiandrogenic activity of DBP (Barlow et al., 2004). Studies show that DBP does not exert its antiandrogenic activity by interacting with AR, but by reducing testosterone synthesis as a result of a reduction in expression of genes involved in cholesterol transport and testosterone synthesis (Foster et al., 2001; Mylchreest et al., 2002; Barlow et al., 2004; Lehman et al., 2004; Thompson et al., 2004). Although the decrease of testosterone levels indicates a possible primary perturbation of Leydig cells, the early onset of Leydig-cell hyperplasia and the presence of germ cell proliferation observed by Mylchreest et al. (2002) also suggest an effect of DBP on the seminiferous cords and Sertoli cells. 


\section{BBP (Benzyl Butyl Phthalate, C4 Backbone)}

\section{Effects on Reproductive Organs and Fertility}

BBP is classified according to EU criteria as a reproductive toxicant: Repro cat. 2: R61-May cause harm to the unborn child, and R62-Possible risk of impaired fertility (ECB, 2004c).

Rats Several studies investigating effects on fertility and/or reproductive organs by administration of BBP by gavage or in the diet have been reported. The main reproductive effects reported in studies with rats exposed to BBP and its two major metabolites MBuP and MBeP were a decrease in relative weight and damage to testis, damage to epididymis, prostate, and seminal vesicle, reduced epididymal sperm concentrations, and reduced fertility (at high BBP concentrations), in addition to increases in relative liver and kidney weights.

Effects as reduced mating and fertility indices, decrease in testis weight, histopathological changes in testis, and hormonal changes have been observed in the majority of the studies at dose levels equal to or higher than dose levels at which effects such as relative organ weight changes and in some studies histopathological changes in liver and other organs were observed. However, signs of testicular toxicity as a dose-dependent decrease in epididymal spermatozoa concentration, atrophy of the testis, and decreased testosterone and follicle-stimulating hormone (FSH) levels were observed in absence of effects on other organs. When taking all the available data into account, the established overall NOAEL for effects on reproductive organs was set to $100 \mathrm{mg} / \mathrm{kg}$ bw/day. This NOAEL was based on observed atrophy of the testis, epididymis, and seminal vesicle and reduced reproductive organ weights at 10 or 18 weeks of age in the F1 generation at $500 \mathrm{mg} / \mathrm{kg} \mathrm{bw/day.}$

The effects on reproductive organs and fertility observed were far more severe and in most studies only observed in animals exposed to BBP during development of the reproductive tract (in utero during late gestation and during lactation), compared to animals that were exposed as adults. However, the age of the animals exposed to BBP in the studies was not always clear.

In addition to the effects already described in reproductive and developmental studies, other developmental effects on male offspring, indicative especially of an antiandrogenic activity of BBP and its metabolites, were observed. These effects included significantly reduced AGD (at dose $250 \mathrm{mg} / \mathrm{kg}$ bw/day), significant increase in number of pups with one or more nipples and areolae (normally not observed in control animals), undescended testis (at dose $750 \mathrm{mg} / \mathrm{kg} \mathrm{bw} /$ day), retarded transdominal descent of the testis (at dose $270 \mathrm{mg} / \mathrm{kg} \mathrm{bw} /$ day), missing or reduced in size epididymis $(750 \mathrm{mg} / \mathrm{kg}$ bw), and hypospadias ( $750 \mathrm{mg} / \mathrm{kg}$ bw/day).

The only effects on reproductive organs observed on female rats in one two-generation study were significantly reduced absolute and relative paired ovaries weight in F0 females (at $750 \mathrm{mg} / \mathrm{kg}$ bw/day), and uterus weight (from $750 \mathrm{mg} / \mathrm{kg}$ bw/day). In F1 females a delay in acquisition of puberty evident as delay in vaginal patency was observed (at $750 \mathrm{mg} / \mathrm{kg}$ bw/day), and in F1 parent females, absolute and relative uterus weight was significantly increased.

Humans In a human study in which the relation between exposure to phthalates and semen quality was investigated, an association between high levels of MBuP and/or MBeP in urine and altered semen quality (semen morphology, concentration, and motility) was found. However, it could not be concluded that the altered semen quality was only a consequence of exposure to BBP.

\section{Developmental Effects Other Than Effects on Reproductive Organs}

Mice Only one developmental study on mice was reported. In this study pregnant mice were exposed from GD6 to GD15 to BBP in feed. At a concentration of $0.5 \%$ in feed (corresponding to $910 \mathrm{mg} / \mathrm{kg}$ bw/day), slight maternal toxicity as significantly reduced weight gain was observed. At this same dose level there was also significant developmental toxicity, evident as significantly increased fetal death per litter and significant increase in percent of malformed foetuses per litter. No information on the type of malformations was given.

Rat In developmental toxicity studies with rats, after oral exposure to BBP and its two major metabolites MBuP and MBeP developmental effects such as prenatal mortality, reduced fetal weight, and malformations of the fetuses were observed in the offspring. Maternal toxic effects, mainly evidenced as reduced body weight gain, decrease in food consumption, and increased liver weight, were observed at doses higher, equal, or lower than doses producing developmental effects.

Developmental effects other than effects on reproductive organs observed in several tests were significantly reduce body weight of the offspring, embryotoxicity (evidenced as significantly increased incidence of total resorptions of all implanted embryos, significantly increased incidence in postimplantation loss per litter), and malformations, such as external malformations (cleft palate), skeletal malformations (fusion of sternebrae, fusion of cervical or thoracic vertebral arches, fusion of thoracic vertebral bodies, absence of lumbar vertebral arches and fusion or absence of ribs), and internal malformations (dilatation of renal pelvis). Embryotoxicity and malformations were mostly observed at dose levels equal or higher than $500 \mathrm{mg} / \mathrm{kg}$ bw, when also signs of maternal toxicity (if measured) were observed. In studies performed by Ema and coworkers where pair-fed rats were used as the reference, an increase of incidence of malformations was observed in the treated groups. Postimplantation loss was observed when dams were exposed on gestation days $0-20,0-7,0-8,0-$ $11,7-9,10-12,13-15$, and 7-16 but not after exposure on gestation days 16-20 and 11-20 compared to control and pair-fed animals. When pseudo-pregnant dams were exposed to BBP on days 
0-8 of pseudo-pregnancy, at dose level $750 \mathrm{mg} / \mathrm{kg} \mathrm{bw} /$ day and higher uterine decidual growth was detected, which indicates that early embryonic loss may at least in part be mediated via a suppression of uterine decidualisation. The conclusion was that the teratogenic effects observed after oral exposure to BBP during organogenic period are primarily the result of exposure to BBP, and not a result of the reduced body-weight gain observed in the dams.

Several studies were reported, where teratogenic phase specificity during gestation was studied. In these studies teratogenic effects were observed when animals were exposed during days 7-9 and 1315 of gestation, but not when exposed during days 10-12 of gestation.

A few studies in which effects of exposure to very low concentrations of BBP in drinking water during gestation and early postnatal life were reported. The overall conclusion for these studies was that exposure to very low concentrations of BBP in drinking water during gestation and early postnatal life does not cause impairment of reproductive system in offspring.

\section{Information on Possible Mechanisms of Action}

In studies, where developmental effects of the two major metabolites of BBP-MBuP and MBeP-were studied, the pattern of developmental toxic effects produced by these two metabolites were similar to those produced by BBP, suggesting that MBuP and MBeP may be responsible of the embryotoxic and/or teratogenic effects observed after exposure to BBP.

Several in vitro studies were performed to assess the estrogenic activity of BBP and its metabolites MBuP and MBeP. In the assays performed, BBP showed only weak estrogen activity at high concentrations, and in these assays $17 \mathrm{~b}$-estradiol $\left(E_{2}\right)$ was approximately $10^{4}$ to $10^{6}$ more potent than BBP. MBuP and MBeP did not exhibit any estrogenic activity in a recombinant yeast screen assay.

The estrogenic activity of BBP, MBuP, and MBeP was studied in several in vivo uterotrophic assays. $\mathrm{BBP}$ and MBuP did not promote uterine growth in immature female rats exposed orally, whereas MBeP caused a significant reduction in absolute and relative uterine weight in one study. However, in view of results in other studies, this study was considered of limited importance in the evaluation of estrogenic activity of BBP in vivo.

Antiandrogen activity was studied in vitro in a recombinant yeast screen assay (yeast cells expressing the androgen receptor), which included assays to investigate the ability of BBP to interact as both an agonist and an antagonist. BBP showed no androgen activity, but was a potent antiandrogen, as potent as the known antiandrogen flutamide.

Effects indicating a possible antiandrogenic activity of BBP and its metabolites MBuP and MBeP were reported in eight in vivo studies. These effects included reduced testicular weight, reduced anogenital distance, and retarded transabdominal descendent of the testis in male offspring exposed during late gestation and lactation.

The authors of a study in which effects on development and on maternal and embryonic zinc metabolism were investigated concluded that BBP was not a strong inducer of MT (metallothionein) and concluded that teratogenic effects after exposure to BBP are most probably not produced due to alternations in maternal and embryonic $\mathrm{Zn}$ metabolism.

\section{DnHP (Di-n-Hexyl Phthalate, C6 Backbone)}

\section{Effects on Reproductive Organs and Fertility}

In a continuous breeding protocol test with mice, DnHP exposure resulted in a dose-related reduction in the proportion of pairs able to produce even a single litter. No litters were produced at the high dose of $1670 \mathrm{mg} / \mathrm{kg} \mathrm{bw} / \mathrm{day}$, only one litter was produced at dose of $800 \mathrm{mg} / \mathrm{kg} \mathrm{bw} / \mathrm{day}$, and 14 of 17 pairs had litters at dose $380 \mathrm{mg} / \mathrm{kg}$ bw/day, compared to all pairs having litters in the control. The numbers of litters per pair, the number of live pups per litter, and the proportion of pups born alive were also significantly affected by DnHP exposure. Significant effects occurred at the lowest dose level, with clear adverse effects seen in the absence of any body weight effects. In a cross mating of the high-dose males with control dams there was a significant reduction in mating (56\%) and only one male sired a litter. In this study only the control and high-dose males were necropsied. Sperm assessment showed a significant decrease in sperm number and motility parameters. Only 3 of 18 males had sufficient number of sperm to allow assessment of abnormal form. There were significant decreases in the relative weights of epididymis, testis, and seminal vesicle. There was significant atrophy of the seminiferous epithelium with mature sperm markedly diminished in the epididymis. In a cross mating of the high-dose females with control males there was no decrease in copulatory plugs, but only one female became pregnant. No treatment-related microscopic lesions were detected in the ovaries, uterus, or vagina of the female mice. Uterine weight was significantly decreased.

Testicular atrophy was observed in a study with 4-week-old rats gavaged for 4 days with DnHP at dose level $2400 \mathrm{mg} / \mathrm{kg}$ bw/day and in the absence of effects on body weight. Dietary exposure of 4week-old rats to $1824 \mathrm{mg} / \mathrm{kg}$ bw/day in another study did not cause any atrophy of the testis.

\section{Developmental Effects Other Than Effects on Reproductive Organs}

In a study where mice were exposed to dose $9900 \mathrm{mg} / \mathrm{kg}$ bw/day (from day 6-13 of gestation) no litters were produced. 


\section{Information on Possible Mechanisms of Action}

DnHP has been studied in an in vitro assay, to determine the mechanism of testicular toxicity. The findings suggest that germ cell loss following in vivo exposure to DnHP is secondary to toxic effects caused to Sertoli cells.

Limited information is available for this chemical considering species sensitivity. The continuous breeding study in mice show that at the lowest dose tested of $380 \mathrm{mg} / \mathrm{kg}$ bw still severe effects are observed. In the developmental toxicity study the most critical period was not tested.

\section{DEHP [Bis(2-ethylhexyI) Phthalate, C6 Backbone]}

DEHP is classified according to EU criteria as reproductive toxicant and labeled as Repro cat. 2: R61May cause harm to the unborn child, and R60-May impair fertility (ECB, 2004c).

Available data demonstrate that DEHP affects both fertility and reproduction in rodents of both sexes and also produces developmental effects in offspring. In males, DEHP induces severe testicular effects, including testicular atrophy. Developing male rats have been found to be more sensitive than sexually mature animals. Irreversible effects occur in rats exposed during the prenatal period and during suckling.

\section{Effects on Reproductive Organs and Fertility}

Mice In a continuous breeding study with mice dietary concentrations of $0.1 \%(200 \mathrm{mg} / \mathrm{kg} \mathrm{bw})$ and $0.3 \%(600 \mathrm{mg} / \mathrm{kg} \mathrm{bw})$ produced significant and dose-dependent decrease in fertility and in the number and proportion of live pups. In a crossover mating study with $\mathrm{F}_{0}$ where treated males and females were mated with control females and males, reduction in fertility was observed in both sexes; only 4 litters out of 20 were born from treated males and no pups were born from treated females. Effects observed on reproductive organs at the highest dose were significantly reduced weight of the testes, epididymis, prostate, and seminal vesicles, some degree of bilateral atrophy of the seminiferous tubules, a significant decrease of percent motile sperm, a significantly decreased sperm concentration in cauda epididymis, and increased incidence of abnormal sperm forms. In female mice, DEHP induced significant reduction in weights of ovaries and oviducts and of uterus. In the high-dose group, DEHP did not significantly decrease the body weight gain, but increased absolute and relative liver weight was observed. The NOAEL in this study was set to $20 \mathrm{mg} / \mathrm{kg} \mathrm{bw} /$ day, the lowest dose tested.

In a two-generation study in which effects on growth, development, and reproductive performance of the $F_{1}$ generation after prenatal exposure to DEHP were investigated, the percentage of prenatal mortality for $F_{1}$ litters was increased and percent of neonatal survival was significantly decreased at the highest dose tested-0.05\% (equivalent to $95 \mathrm{mg} / \mathrm{kg}$ bw/day).

In a continuous breeding study at a dose level of $150 \mathrm{mg} / \mathrm{kg}$ bw/day a reduction in epididymal and testicular weights and of sperm motility and an increased number of abnormal sperm cells were observed.

In a study where mice ( 6 weeks old at the beginning of the study) were exposed in the diet to concentrations of $0,100,500,1500$, and $6000 \mathrm{ppm}$ for 104 weeks (equivalent to; $0,19.2,98.5$, 292.2 , or $1266 \mathrm{mg} / \mathrm{kg} /$ day) a significant decrease in testicular weight and an increased incidence and severity of bilateral hypospermia and associated incidence of immature/abnormal sperm forms and hypospermia in epididymis were observed at a concentration of $1500 \mathrm{ppm}(292.2 \mathrm{mg} / \mathrm{kg} \mathrm{bw} / \mathrm{day})$. The NOAEL for testicular effects in this study was $500 \mathrm{ppm}$, corresponding to $98.5 \mathrm{mg} / \mathrm{kg}$ bw.

Rats A large number of studies on rats investigating effect on fertility and on reproductive organs after exposure to DEHP were reviewed. Only some of the studies considered most relevant and their conclusions are summarized next.

The lowest NOAEL for testicular effects in a 13-week dietary repeated-dose study in rats was set to $3.7 \mathrm{mg} / \mathrm{kg} \mathrm{bw} /$ day based on a high incidence of Sertoli cell vacuolation at dose level of $37.6 \mathrm{mg} / \mathrm{kg}$ bw/day. Testis weights were decreased at $376 \mathrm{mg} / \mathrm{kg}$ bw but not at lower doses.

In a study where adult rats were administrated DEHP in a diet, at the two highest doses -5000 and $20000 \mathrm{ppm}$ (equivalent to 284 and $1156 \mathrm{mg} / \mathrm{kg} \mathrm{bw} /$ day, respectively) - a dose-dependent reduction in total body, testis, epididymis, and prostate weights was observed, At the highest dose, significantly reduced mean litter size was also observed, which was correlated with degenerative changes in the testes, along with decreased testicular zinc content, significant reduction in epididymal sperm density and motility, and increased incidence of abnormal sperm. There also was a trend toward decreased, but not statistically significantly, testosterone and increased luteinizing hormone (LH) and folliclestimulating hormone (FSH) in serum at the two highest doses. The NOAEL of this study was $69 \mathrm{mg} / \mathrm{kg}$ bw/day.

In a two-generation range-finding study in Wistar rats, effects on both fertility and developmental effects were observed. Rats were exposed to dietary levels of $0,1000,3000$, or 9000 ppm DEHP (corresponding approximately to $0,110,339$, or $1060 \mathrm{mg} / \mathrm{kg}$ bw/day). In the $F_{0}$ generation significantly increased mean absolute liver weight was observed in females at $1000 \mathrm{ppm}$, while the mean relative liver weight was significantly increased in both sexes at 3000 and 9000 ppm. The food consumption and body weight gain were significantly reduced in $\mathrm{F}_{0}$ females during premating, gestation, and lactation at a dose of $9000 \mathrm{ppm}$. At the highest dose level, the postimplantation loss was significantly increased; the total number of delivered $F_{1}$ pups, the mean number of delivered pups 
per dam, and the survival on postpartum day 0 and 4 were significantly reduced. In pups of both sexes, the mean body weight was reduced until weaning and body weight gain was retarded. Effects on the $F_{1}$ male animals were treatment-related loss in spermatocytes at the two highest dose levels, significantly increased presence of areolas/nipples and delayed sexual maturation (based on preputial separation), reduced fertility, and significant decreases in relative testicular weight, absolute epididymal weight, size of epididymis and testes, focal or diffuse atrophy of spermatogenesis of the testes, and diffuse Leydig-cell hyperplasia in all males; interstitial edema in the testes altered spermatogenesis in the epididymis at the highest dose level. At this dose level, premating mortality of $3 / 9$ males occurred. Sertoli cell vacuolation was recorded at $1000 \mathrm{ppm}$. In females, the sexual maturation was delayed, based on vaginal opening. The total number of live-born $F_{2}$ pups was reduced at a dose level of 3000 ppm; at a dose level of 9000 ppm the mean number of live pups/dam was also significantly reduced.

In a study in which effects of DEHP on spermatogenesis of adult male rats, the authors concluded that DEHP causes a decrease in testicular function after short-time dosing already at dose level $250 \mathrm{mg} / \mathrm{kg}$ bw/day.

Several studies conducted to determine the age dependency of induction of effects of DEHP on male reproductive organs showed that DEHP causes more severe and irreversible effects on developing male rats than in adult rats, particularly when are exposed in utero and during lactation.

A highly significant and dose-related reduction in absolute and relative testicular weight and severe histopatological damage (gross disorganization of the seminiferous tubule structure, detachment of spermatogonia from basal membrane, absence of spermatocytes) to the testis was observed after exposure of rats from gestation day 1 to postnatal day 21 to DEHP in drinking water at dose levels corresponding o $3.0-3.5 \mathrm{mg} / \mathrm{kg}$ bw/day and $30-35 \mathrm{mg} / \mathrm{kg}$ bw/day. The LOAEL in this study was set to $3.5 \mathrm{mg} / \mathrm{kg}$ bw/day.

Gestational and lactational exposure to DEHP at a dose level of $750 \mathrm{mg} / \mathrm{kg}$ bw/day caused statistically increased incidence in reproductive and nonreproductive malformations. The reproductive malformations observed were hypospadias, vaginal pouch, ventral prostate agenesis, testicular and epididymal atrophy or agenesis, retained nipples, and hemorrhagic testis.

Moore et al. (2001) studied effects on sexual development by exposing rats to DEHP (dose levels of 0 , 375,750 , and $1500 \mathrm{mg} / \mathrm{kg}$ bw/day) in utero and during lactation (from gestation day 3 until postnatal day 21). Maternal toxicity indicated as significantly reduced maternal weight gain was observed in the middle-and high-dose groups at gestation days 16-20, but not between birth and weaning. The number of pups born per dam was significantly reduced in the high dose group. In the middle-and high-dose groups there was also a dose-related increase in postnatal mortality, but this was not statistically significant. Dose-related reduction in body weight was observed at $750 \mathrm{mg} / \mathrm{kg}$ bw/day, but was statistically significant only for male pups. Significant effects on male pups observed were reduced anogenital distance, areola and nipple retention, undescended testis, incomplete preputial separation; reduced weight of testis, epididymis, glans penis, ventral, dorsolateral and anterior prostate, and seminal vesicle; anterior prostate agenesis (very high incidence), partial or complete ventral prostate agenesis, occasional dorsolateral prostate, and seminal vesicle agenesis; and reduced sperm counts and testicular and penile malformations. Most of these effects were statistically significant at the two highest doses; however, many of them (reduced anogenital distance, areola and nipple retention, undescended testis, incomplete preputial separation, ventral prostate agenesis) were observed already at the lowest dose. No significant effects on reproductive development of female rats were observed. Many males that were exposed to DEHP were sexually inactive in the presence of control females, and this did not correlate with the incidence of abnormal reproductive organs. The author suggested that in utero and lactational exposure inhibited sexual differentiation of the CNS.

In a recent lifetime experiment with doses of 30,95 , and $300 \mathrm{mg} / \mathrm{kg}$ used on Sprague-Dawley (according to the author, this strain was chosen, because it shows low level of spontaneous Leydig-cell tumors incidence) rats performed by Voss et al. (2004), chronic DEHP exposure that was extended to the point when standard carcinogenicity studies are already terminated induced Leydig-cell tumors in the testes of the adult rats. The incidence of Leydig-cell tumors was significant in the high-dose group ( $300 \mathrm{mg} / \mathrm{kg} \mathrm{bw/day);} \mathrm{however,} \mathrm{a} \mathrm{significant} \mathrm{dose-related} \mathrm{trend} \mathrm{over} \mathrm{all} \mathrm{dose} \mathrm{groups} \mathrm{was} \mathrm{observed}$ together with multiplicity of these tumors. Furthermore, in this study, Leydig-cell tumors occurred with significantly higher incidence earlier than hepatocellular tumors.

Akingbemi et al. (2001) investigated the ability of DEHP to affect Leydig-cell production of testosterone $(T)$ at different stages of development. Male rats were exposed to DEHP by exposing pregnant dams by gavage during gestation $(100 \mathrm{mg} / \mathrm{kg}$ bw/day from gestation day 12 to 21$)$ and lactation ( $100 \mathrm{mg} / \mathrm{kg}$ bw/day from postnatal day 1 to 21 ). Prepubertal rats were exposed by gavage (dose levels $0,1,10,100$, or $200 \mathrm{mg} / \mathrm{kg} \mathrm{bw} /$ day) for 14 days at two different periods (from postnatal day 21-34 or 35-48), and for 28 days (from postnatal day 21 to 48 . Furthermore young adult rats were exposed to same dose levels for 28 days (postnatal day 62-89). Body weights of dams and male pups exposed during gestation and lactation were not affected. In male pups exposed to during gestation adversely affected Leydig cells' production of testosterone, as serum levels were significantly lower at postnatal day 21 and 35. Depression of T levels was associated with reduced LH

concentrations. However, at postnatal day 90, all levels were similar to the control, which suggests reversibility of these effects. In males exposed during lactation, the only effect observed was slightly reduced serum $T$ concentrations at 21 days; no differences in serum LH levels were observed. In prepubertal and young adult rats exposed, no signs of systemic toxicity were observed at any dose 
level. Serum T and LH levels and testis and seminal vesicle weights were not affected, but from dose level $10 \mathrm{mg} / \mathrm{kg}$ bw/day a reduction in Leydig-cell T production was observed. In prepubertal rats exposed for 28 days, a dose-dependent increase in the serum concentrations of T and LH was observed and increased production of T by Leydig cells. In exposed young adult rats no effects on serum hormone levels or Leydig-cell T production were observed. The observed inhibition of T production in this study was associated with decrease in pituitary secretion of LH and with reduced activity of steroidogenic enzymes.

In female rats exposed by gavage to DEHP at dose level $2000 \mathrm{mg} / \mathrm{kg}$ bw/day for 1-12 days, effects observed were prolonged estrus cycles, suppressed or delayed ovulation, and increased incidence of females that have not ovulated by vaginal estrus, and smaller preovulatory follicles due to smaller granulosa cells. Due to suppressed serum estradiol levels there was a secondary increase in the level of FSH and there was no stimulation of LH surge, necessary for ovulation. The authors of the study concluded, that exposure to DEHP causes hypoestrogenic anovulatory cycles and polycystic ovaries in adult female. In another study, the author concluded that DEHP treatment alters oestrus cycle and causes changes of testosterone and estradiol levels in animals in diestrus.

Other Animal Species Effects on testes were observed in ferret (LOAEL set to $1200 \mathrm{mg} / \mathrm{kg} \mathrm{bw/day).}$ In hamster, minor effects were observed with DEHP and more severe ones with MEHP. In marmosets no testicular effects were observed after exposure to DEHP.

\section{Developmental Effects Other Than Effects on Reproductive Organs}

Mice There were few developmental studies with mice reviewed. In a study in which dams were exposed in feed from gestation day 1 to 17 at dose levels corresponding to $0,44,91,190.6$, and $292.5 \mathrm{mg} / \mathrm{kg}$ bw/day, the effects observed were significantly increased incidence of resorptions and late fetal deaths and number of dead and malformed fetuses, and significantly reduced fetal weight and number of live fetuses per litter from the dose level of $190.6 \mathrm{mg} / \mathrm{kg} \mathrm{bw} / \mathrm{day}$. The percentage of fetuses with malformations and percentage of malformed foetuses per litter were increased significantly from the dose level of $91 \mathrm{mg} / \mathrm{kg}$ bw/day. Malformations observed were external (unilateral or bilateral open eyes, exophthalmia, exencephaly, malformations or absence of the tail), visceral (malformations of the major arteries), and skeletal (fused and branched ribs, misalignment and fused thoracic vertebral centra). Maternal toxicity-reduced body weight gain (mainly due to reduced gravid uterine weight) was observed from a dose level of $91 \mathrm{mg} / \mathrm{kg} \mathrm{bw} /$ day. The NOAEL for maternal toxicity was set at $91 \mathrm{mg} / \mathrm{kg}$ bw/day, while the NOAEL for developmental toxicity was set at $44 \mathrm{mg} / \mathrm{kg}$ bw/day.

In another developmental study, the NOAEL for developmental effects was set at $40 \mathrm{mg} / \mathrm{kg}$ bw/day, due to slightly higher incidence of fetuses with intramuscular or nasal hemorrhage or dilated orbital sinuses and a small number of fetuses with anomalies of blood vessels at $200 \mathrm{mg} / \mathrm{kg}$ bw/day. The NOAEL for maternal toxicity in this study was set at $200 \mathrm{mg} / \mathrm{kg}$ bw/day.

Rats In developmental studies with rats, DEHP was shown to be embryotoxic at maternal toxic dose levels or dose levels close to those that which produced maternal toxicity. In a study in which dams were exposed from gestation day 6 to 15, severe developmental effects observed were observed at dose level $1000 \mathrm{mg} / \mathrm{kg}$ bw/day. The effects observed were statistically significant increased implantation loss, lower number of live fetuses per dam, decreased fetal body weights, highly increased incidence of external, soft tissue, and skeletally malformed fetuses per litter (malformations of the tail, brain, urinary tract, gonads, vertebral column, sternum), and increased percentage of fetuses per litter with soft-tissue and skeletal variations and retardations. At this dose level maternal toxicity was noted as slightly reduced food consumption, and reduced uterus weight, which was associated with high embryolethality and statistically increased relative kidney and liver weight. The maternal and developmental NOAEL in this study was set at $200 \mathrm{mg} / \mathrm{kg}$ bw/day. In other studies, developmental effects were observed at approximately the same dose levels.

\section{Information on Possible Mechanisms of Action}

MEHP is believed to be the active metabolite of DEHP affecting testes and reproductive functions both in vitro and in vivo, as similar effects were observed after exposure to MEHP as after exposure to DEHP and in some studies MEHP appeared to be more toxic than DEHP. The role of other metabolites is not fully elucidated. After administration of DEHP and five of its major metabolites, administration of MEHP caused increase in the number of degenerated spermatocytes and spermatides, while no effects were observed after administration of other metabolites.

The results of several studies show, that DEHP interferes with zinc homeostasis (Oishi and Hiraga, 1980; Foster et al., 1982; Lamb et al., 1987) and reduces levels of zinc in testes. In studies with coadministration of zinc, this did not prevent testicular atrophy. Furthermore, the effects such as pathological lesions and apoptosis occur prior to loss of zinc in the testis (Park et al., 2002), which suggest that loss of zinc cannot be the cause of testicular toxicity, but rather a consequence.

J. Lee et al. (2004) studied the effect of exposure to DEHP during gestation on zinc homeostasis in the embryo by analysis of several key genes related to zinc metabolism. Dams (rats) were exposed on gestation day 9 to doses of $0,50,200$, and $600 \mathrm{mg} / \mathrm{kg}$ bw/day. J. Lee et al. concluded that exposure at reasonably low dose levels during organogenesis can alter several key genes in embryonic zinc homeostasis. They suggested that reductions in embryonic zinc accumulation, secondary to maternal 
DEHP exposure, can increase risk of malformations. Maternal zinc deficiency has been shown to be teratogenic in mammalian species.

Results of several in vitro and in vivo studies showed that the Sertoli cell is one of the main targets of DEHP or its metabolites, causing testicular toxicity and depletion of germ cells. Recent studies suggest that DEHP reduces the FSH stimulation of Sertoli cells.

In vitro and in vivo studies demonstrate that DEHP and MEHP can have a direct effect also on Leydig cells structure and function as determined by testosterone output. It is possible that malfunction of Leydig cells affects physiology of Sertoli cells. Results of a study in which effects of different phthalate esters and their metabolites was studied indicate that different phthalates may cause effects and changes that are common to both Sertoli and Leydig cells or specific to only one type of cells.

The role of testosterone in adverse effects observed in the testis was investigated in several studies. In a study in which, along with exposure to $2000 \mathrm{mg} / \mathrm{kg} \mathrm{bw}$, testosterone was administrated subcutaneously, it seemed that coadministration of testosterone restored the testes weights, sperm count, and activity of the enzymes in the testis. Parks et al. (2000) studied whether the antiandrogenic effects of DEHP observed in rats exposed investigated and during lactation occur by inhibiting testosterone production or by binding to the androgen receptor (AR) by applying a battery of in vitro, ex vivo, and in vivo assays. DEHP and its major metabolite MEHP did not bind AR, but when administrated in vivo at a dose level of $750 \mathrm{mg} / \mathrm{kg}$ bw from gestation 14 to postnatal day 3, testicular testosterone production and testicular testosterone and fetal testosterone levels were reduced to female levels. These changes were initially observed at gestation day 17, when there were no signs of systemic toxicity or fetotoxic effects. Furthermore, an increased number of Leydig cells compared to the control was observed. Parks et al. (2000) hypothesized that DEHP or its metabolite decreases the production of testosterone either by acting directly on Leydig cells or by interfering with Sertolli cells paracrine factors that regulate Leydig cells function and differentiation. If the Leydig cells continue to divide instead of differentiate, this could result in a delay in production of testosterone. If this happens in the critical period of sexual differentiation it can result in malformations of the androgen-dependent tissues and organs.

After observing an increase in the serum concentrations of $\mathrm{T}$ and $\mathrm{LH}$ in prepubertal rats exposed to DEHP for 28 days in one previous study (Akingbemi et al., 2001), Akingbemi et al. (2004) conducted another study in order to determine the effects of LH over stimulation induced by DEHP on Leydig cell steroidogenesis and number. Rats were exposed by gavage to doses 10 or $100 \mathrm{mg} / \mathrm{kg}$ bw/day from postnatal day 21 , to days 48,90 , or 120 . Exposure to DEHP caused high serum levels of LH and T hormone, although the production of $\mathrm{T}$ by the Leydig cells decreased. The author hypothesized that the elevated serum $T$ levels were due to increased number of Leydig cells (as Leydig cells hyperplasia was also observed in DEHP treated rats), not excluding the possibility, that also increased steroidogenesis in other tissues such as adrenals, could contribute to higher T serum levels. Furthermore, an increase of E2 (17b-estradiol) synthesis by Leydig cells was observed at 48 days. At days 48 and 90 , only MEHP was detected in the serum; therefore, the author hypothesized that the effects observed were mostly due to the action of MEHP or/and its metabolites. The author concluded that DEHP is indirectly estrogenic, because it increases serum E2 levels, presumably due to LH induction of aromatase activity in Leydig cells. Simultaneous elevations in serum T and E2 levels suggest the possibility of multiple crosstalk between androgen, estrogen, and steroid hormone receptors, indicating that the mechanisms of chemical-induced effects may be more complex than previously thought.

DEHP did not show any ER-mediated activity in assays in vitro (Zacharewski et al., 1998).

In a recent review paper, Lovenkamp-Swan and Davis (2003) proposed a model for the ovarian action of DEHP. They hypothesized that MEHP (major metabolite of DEHP) activates the PPARs (PPARa and PPARg) to suppress aromatase in granulosa cells, which results in suppression of estradiol production in the ovary and anovulation.

Gazouli et al. (2002) studied in vivo and in vitro the involvement of PPARs (bezafibrate and MEHP) in testicular toxicity, more exactly in Leydig cell function and steroidogenesis. Based on the results of these studies they hypothesized that these two peroxisome proliferators cause PPARa (peroxisome proliferator-activator receptor)-dependent inhibition of Leydig cell PBR (peripheral-type benzodiazepine receptor) gene expression. This leads to a decrease of PBR protein, which controls the amount of cholesterol transport and results in a reduced production of steroids by the Leydig cells.

\section{Di-phC10 [Bis(2-propylheptyl) Phthalate, C7 Backbone)}

\section{Effects on Reproductive Organs and Fertility}

A repeated-dose study of the oral administration of DiphC10 to rats at dietary concentrations of 50 , 250, and $1500 \mathrm{mg} / \mathrm{kg}$ bw/day for 3 months, a period sufficient to cover the complete sperm maturation, led to no effects on the relevant reproductive organs.

\section{Developmental Effects Other Than Effects on Reproductive Organs}

In a prenatal development screening study with rats in which DiphC10 PE was administered to pregnant dams by gavage on day 6 through day 15, no effects on development were observed. Fetal and maternal NOAEL was $1000 \mathrm{mg} / \mathrm{kg}$ bw/day (the highest dose tested). 
In a conventional developmental toxicity study with rats in which dams were administered by gavage doses of 40,200 , and $1000 \mathrm{mg} / \mathrm{kg}$ bw/day on gestation day 6 through day 19 , the high-dose dams showed some systemic effects such as statistically significant reduction in food consumption and body weight gain. At days 19 and 20, statistically significant lowered body weight was observed, which was considered a consequence of high rate of resorptions; in fact, 3 of 25 high-dose dams had no live fetuses at all, but only very early resorptions. Marginal signs of substance-induced effects on fetal morphology, but no indications of teratogenicity were observed at a high dose-the rates of soft tissue, skeletal, and total variations were slightly but statistically significantly increased. A borderline effect on fetal morphology in the $1000-\mathrm{mg} / \mathrm{kg}$ bw/day fetuses could not be ruled out with certainty, but no indications of selective developmental toxicity were observed up to and at $1000 \mathrm{mg} / \mathrm{kg}$ bw/day. The NOAEL for parental and fetal toxicity was $200 \mathrm{mg} / \mathrm{kg}$ bw/day.

Only rats were tested. In the 90-day dietary study no effects were observed. Comparing this study with a similar dietary study of DEHP, the testis weight effects in the latter were observed at 284 $\mathrm{mg} / \mathrm{kg}$ bw/day, while in the first a NOAEL of $1000 \mathrm{mg} / \mathrm{kg}$ bw/day was derived indicating that DEHP is more potent than $\mathrm{Di}$-phC10, but possibly only a factor of 3 . The developmental toxicity studies are similar, both carried out in rats. DEHP was tested during gestation days 6-15, and Di-ph10 during days 6-19. For both studies a NOAEL of 200 was derived for maternal toxicity and developmental effects and in general similar effects were observed.

\section{DnOP (Di-n-octyl Phthalate, C8 Backbone)}

\section{Effects on Reproductive Organs and Fertility}

In a continuous breeding study with mice, no effect other than decrease of relative seminal vesicles weight was observed at dose $7500 \mathrm{mg} / \mathrm{kg}$ in feed, which is roughly $750 \mathrm{mg} / \mathrm{kg} \mathrm{bw} / \mathrm{day}$.

\section{Developmental Effects Other Than Effects on Reproductive Organs}

Effects such as reduced litter size and reduced pup weight gain on postnatal days 1-3 were observed in a Chernoff-Kavlock assay in mice.

In an assay where prenatal toxicity of $n$-octanol, a primary metabolite of DnOP, was administered by gavage to pregnant rats, no effects on fetal weight, viability, or developmental toxicity were observed.

\section{DINP (Di-"Isononyl" Phthalate, Mixture of C6-9 Backbone)}

\section{Effects on Reproductive Organs and Fertility}

In mice, a very high dose of DINP of $5770 \mathrm{mg} / \mathrm{kg}$ bw/day lead to an increase in testicular weight with abnormal/immature sperm forms. In the chronic study a NOAEL of $276 \mathrm{mg} / \mathrm{kg}$ bw/day was assumed for testicular effects based on reduced testicular absolute and relative weight. The NOAEL for systemic toxicity was also $276 \mathrm{mg} / \mathrm{kg}$ bw/day.

In adult rats some minor effects were observed, which were not histologically confirmed in any of the studies. In a recent study with exposure during the late gestational period (dams were dosed single doses of $750 \mathrm{mg} / \mathrm{kg}$ bw/day from gravid day 14 to postnatal day 3), DINP induced a significant level $(7.7 \%)$ of malformations of testis, epididymis, accessory reproductive organs, and external genitalia. At this dose level no signs of maternal toxicity were observed (Gray et al., 2000).

Vaginal hemorrhage was observed in some reproductive toxicity (developmental) studies, but overall, from the reproductive studies in rats and mice, no adverse effects on female fertility may be anticipated.

\section{Developmental Effects Other Than Effects on Reproductive Organs}

With regard to offspring survival in rats, at $1.5 \%$ (range of $966-2246 \mathrm{mg} / \mathrm{kg} \mathrm{bw} /$ day), a decrease in life birth and survival indices was observed in a one-generation range-finding test, but not in a twogeneration study at a dose of $0.8 \%$ (range $477-1541 \mathrm{mg} / \mathrm{kg}$ bw/day). The NOAEL for this effect was set at $622 \mathrm{mg} / \mathrm{kg}$ bw/day.

In developmental studies, visceral (dilated renal pelvis and hydroureter) and skeletal (rudimentary cervical and accessory 14th ribs) variations were significantly increased at $1000 \mathrm{mg} / \mathrm{kg}$ bw/day, which lead to NOAEL of $500 \mathrm{mg} / \mathrm{kg} /$ day. At $1000 \mathrm{mg} / \mathrm{kg} \mathrm{bw} /$ day slight and at $500 \mathrm{mg} / \mathrm{kg}$ bw/day no maternal toxicity was observed.

A decrease of mean offspring body weight was observed following parental administration of DINP in the one-and two-generation studies from the lowest dose tested $0.2 \%$ in the two-generation study. A LOAEL of $159 \mathrm{mg} / \mathrm{kg}$ bw/day was established. In the two-generation studies minor effects on parental animals were observed, such as lower mean body weight and hepatic changes, from a dose of $0.2 \%$.

\section{Information on Possible Mechanisms of Action}

DINP showed no activity in the different assays conducted to test the binding ability to rodent or human estrogen receptors or to induce estrogen receptor-mediated gene expression. DINP showed the ability to stimulate cell proliferation in one in vitro assay. In vivo response obtained with wet weight is considered negative. Results of vaginal epithelial cell cornification assay also exhibit absence of estrogen receptor-mediated estrogenic activity. 
Vaginal hemorrhages that were observed in some reprotoxicity (developmental) studies might be indicative of perturbation of the endocrine homeostasis.

Based on results in a recent study investigating the effects of several phthalates on neonatal rats, among them DINP, the author concluded that DINP might have antiandrogenic potency.

In a chronic mice study a NOAEL of $276 \mathrm{mg} / \mathrm{kg}$ bw was found, with some effect on testis. This NOAEL is similar to that of $\mathrm{Di}-\mathrm{phC10}$ (C7 backbone).

\section{DIDP (Di-"isodecyl" Phthalate, C9 Backbone)}

\section{Effects on Reproductive Organs and Fertility}

In a repeated-dose toxicity study and in a two-generation study there was no indication of effects from DIDP on reproductive organs in 42 to 44 -day-old (pubertal) or adult rats. From those assays, no adverse effects on fertility may be anticipated. In a two-generation study, no adverse effects on reproductive organs were observed in male and female rats at doses up to the highest dose tested, $0.8 \%$ in the diet (corresponding to $427-1582 \mathrm{mg} / \mathrm{kg} \mathrm{bw} /$ day).

\section{Developmental Effects Other Than Effects on Reproductive Organs}

A decrease in survival indices was observed in two two-generation studies, mainly in the F2 generation on day 1 and day 4 from a DIDP concentration in the feed of $0.2 \%$ (corresponding to a dose level 114 to $225 \mathrm{mg} / \mathrm{kg}$ bw/day), leading to a NOAEL of $33 \mathrm{mg} / \mathrm{kg}$ bw/day. A NOAEL of 500 $\mathrm{mg} / \mathrm{kg}$ bw/day was assumed for skeletal variations and for maternal toxicity. The observed decrease in survival indices and skeletal variations indicate that DIDP is a developmental toxicant; however, the effects were not severe enough to justify classification for developmental effects.

\section{Information on Possible Mechanisms of Action}

No estrogenic activity was shown in both in vivo and in vitro tests.

On the whole, no overt effects related to endocrine disruption of the reproductive system have been observed.

No effects were seen on the reproductive organs in a repeated-dose and two-generation study, indicating a lower potency than for the shorter chain phthalates.

The developmental effects such as decrease of survival indices were led to an NOAEL of $33 \mathrm{mg} / \mathrm{kg} \mathrm{bw}$ (LOAEL was around $100-200 \mathrm{mg} / \mathrm{kg} \mathrm{bw}$ ), roughly in line with DEHP.

Di-C9-11 (1,2-Benzenedicarboxylic Acid, DiC9-11 Branched and Linear Alkyl Esters, C10 Backbone)

\section{Effects on Reproductive Organs and Fertility}

In a two-generation reproductive toxicity study in rats there was no impairment of fertility, fecundity, or development in either generation. The NOAEL for reproductive endpoints is $1000 \mathrm{mg} / \mathrm{kg} \mathrm{bw} /$ day (the highest dose tested); for general toxicity the NOAEL is $500 \mathrm{mg} / \mathrm{kg}$ bw/day.

\section{Developmental Effects Other Than Effects on Reproductive Organs}

In a developmental toxicity study where dams were dosed by gavage doses of $0,250,500$, or 1000 $\mathrm{mg} / \mathrm{kg}$ bw/day on gestation days 1-19 no malformations were observed at any dose. The NOAEL for maternal toxicity was $1000 \mathrm{mg} / \mathrm{kg} /$ day and the developmental NOAEL was $250 \mathrm{mg} / \mathrm{kg}$ bw/day, based on minor skeletal and visceral variations (increased incidence of supernumerary lumbar ribs) at 500 $\mathrm{mg} / \mathrm{kg}$ bw/day, which are not considered to be indicative of a teratogenic effect.

\section{ACKNOWLEDGMENTS}

This work was carried at RIVM in cooperation with the Utrecht University in the Netherlands. The Utrecht University is acknowledged for a scholarship for the first author. We thank Gerlienke Schuur, Jean-Paul Rila, and Betty Hakkert from RIVM and Bas Blaauboer from Utrecht University for their critical comments. 


\section{REFERENCES}

Akingbemi, B. T., Youker, R. T., Sottas, C. M., Ge, R., Katz, E., Klinefelter, G. R., Zirkin, B. R., and Hardy, M. P. Modulation of rat Leydig cell steroidogenic function by di(2-ethylhexyl)phthalate. Biol. Reprod. (2001), 65: 1252-1259.

Akingbemi, B. T., Ge, R., Klinefelter, G. R., Zirkin, B. R., and Hardy, M. P. Phthalate-induced Leydig cell hyperplasia is associated with multiple endocrine disturbances. Proc. Natl. Acad. Sci. USA (2004), 101: 775-780.

Albro, P. W., and Lavenhar, S. R. Metabolism of di(2-ethylhexyl)phthalate. Drug Metabol. Rev. (1989), 21: 13-34 .

Barlow, S., Kavlock, R. J., Moore, J. A., Schantz, S. L., Sheehan, D. M., Shuey, D. L., and Lary, J. M. Teratology Society Public Affairs Committee position paper: Developmental toxicity of endocrine disruptors to humans. Teratology (1999), 60: 365-375.

Barlow, N. J., Philips, S. L., Wallace, D. G., Sar, M., Gaido, K. W., and Foster, P. M.D. Quantitative changes in gene expression in fetal rat testes following exposure to di(n-butyl) phthalate. Toxicol. Sci. (2003), 73: 431-451.

Barlow, N. J., McIntyre, B. S., and Foster, P. M.D. Male reproductive tract lesions at 6, 12, and 18 months of age following in utero exposure to di(n-butyl) phthalate. Toxicol. Pathol. (2004), 32: 7990.

Blount, B. C., Silva, M. J., Claudill, S. P., Needham, L. L., Pirkle, J. L., Sampson, E. J., Lucier, G. W., Jackson, R. J., and Brock, J. W. Levels of seven urinary phthalate metabolites in a human reference population. Environ. Health Perspect. (2000), 108: 979-982.

Bodar, C., De Bruijn, J., Vermeire, T., and Van der Zandt, P. Trends in risk assessment of chemicals in the European Union. Hum. Ecol. Risk Assess. (2002), 8: 1825-1843.

Colon, I., Caro, D., Bourdony, C. J., and Rosario, O. Identification of phthalate esters in the serum of young Puerto Rican girls with premature breast development. Environ. Health Perspect. (2000), 108: 895-900.

Combes, R., Barratt, M., and Balls, M. An overall strategy for the testing of chemicals for human hazard and risk assessment under the EU REACH system. ATLA (2003), 31: 7-19.

Cronin, M. T.D., Jaworska, J. S., Walker, J. D., Comber, M. H.I., Watts, C. D., and Worth, A. P. Use of QSARs in international decision-making frameworks to predict health effects of chemical substances. Environ. Health Perspect. (2003), 111: 1391-1401.

Damstra, T., Barlow, S., Bergman, A., Kavlock, R., and Van Der Kraak, G. Global assessment of the state-of-the science of endocrine disruptors WHO IPCS. WHO IPCS EDC 02.2s: Geneva, (2002) www.who-int/ipcs/publications/new_issues/endocrinedisruptors/en/.

Danish, EPA Report on the advisory list of self-classification of dangerous substances Environmental project no. 636: Denmark, (2001) http://www.mst.dk/homepage(accessed 12 2004).

DiGangi, J., Schettler, T., Cobbing, M., and Rossi, M. Aggregate exposures to phthalates in humans. In Health Care Without Harm 1-49, (2002) http://www.nottoopretty.org/images/PhthalatesReportLong.pdf(accessed 11 2004).

ECB Bis(2-ethylhexyl) phthalate draft risk assessment report Consolidated final report. Chapters 4-6., (2001) http://ecb.jrc.it/(accessed 10 2004).

ECB White paper strategy for future chemicals policy European Commission, (2001b) http://ecb.jrc.it/ accessed 102004.

ECB European Union Risk Assessment Report, 1,2-Benzenedicarboxylic acid, di-C8-10-branched alkyl esters, C9-rich and di-"isononyl" phthalate (DINP) Institute for Health and Consumer Protection; 2nd Priority list, (2003a), Volume 35 http://ecb.jrc.it/esis/esis.php?PGM=ora.

ECB European Union Risk Assessment Report, 1,2-Benzenedicarboxylic acid, di-C9-11-branched alkyl esters, C10-rich and di-"isodecyl" phthalate (DIDP) Institute for Health and Consumer Protection; 2nd Priority list, (2003b), Volume 36 http://ecb.jrc.it/esis/esis.php?PGM=ora.

ECB Technical guidance document in support of the Commission Directive 9367 EEC on risk assessment for new substances, Commission Regulation (EEC) No. 148894 on risk assessment for existing substances, and Directive $988 \mathrm{EC}$ of the European Parliament and of the Council concerning the placing of biocidal products on the market Part 3. European Commission, (2003c) http://ecb.jrc.it (accessed 11 2004).

ECB Draft risk assessment report, Benzyl butyl phthalate Draft March, (2004a) http://ecb.jrc.it (accessed 10 2004).

ECB European Union Risk Assessment Report, Dibuthyl phthalate 1st Priority list. Institute for Health and Consumer Protection, (2004b), Volume 26 http://ecb.jrc.it/esis/esis.php?PGM=ora.

ECB Search Appendix I to Directive 67548 EEC on classification and labeling of dangerous substances, (2004c) Last updated 3004 2004bhttp://ecb.jrc.it/classification-labelling (accessed 11 2004).

ECETOC Workshop on regulatory acceptance of (Q)SARs for human health and environmental endpoints Setubal: Portugal, (March, 2002). 
ECVAM Alternative (non-animal) methods for chemicals testing: Current status and future prospects $A$ report prepared by ECVAM and the ECVAM Working Group on Chemicals. European Commission, IHPC, (2002) http://ecvam.jrc.it/publication/Preamble.pdf.

ECVAM Development of a novel approach in hazard and risk assessment of reproductive toxicity by a combination and application of in vitro, tissue and sensor technologies University of Konstanz and ECVAM (JRC Ispra), (2003).

Ema, M., Miyawaki, E., and Kawashima, K. Critical period for adverse effects on development of reproductive system in male offspring of rats given di-n-butyl phthalate during late pregnancy. Toxicol. Lett. (2000), 111: 271-278.

Enterprise Directorate General, Environment Directorate General REACH in brief European Commission. 15.09.2004, (2004) http://ecb.jrc.it (accessed 12 2004).

European Commission Proposal concerning the Registration, Evaluation, Authorisation and Restriction of Chemicals (REACH) COM, (2003) (2003)644 final (29 October)http://europa.eu.int/eurlex/en/com/pdf/2003/com2003_0644en.html (accessed 11 2004).

Fennel, T. R., Krol, W. L., Summer, S. C.J., and Snyder, R. W. Pharmacokinetics of dibutylphthalate in pregnant rats. Toxicol. Sci. (2004), 82: 407-418.

Fisher, J. S. Environmental anti-androgens and male reproductive health: Focus on phthalates and testicular dysgenesis syndrome. Reproduction (2004), 127: 305-315.

Fisher, J. S., Macpherson, S., Marchetti, N., and Sharpe, R. M. Human "testicular dysgenesis syndrome": A possible model using in-utero exposure of the rat to dibuthyl phthalate. Hum. Reprod. (2003), 18: 1383-1394.

Foster, P. M.D., Thomas, L. V., Cook, M. W., and Gangolli, S. D. Study of the testicular effects and changes in zinc excretion produced by some n-alkyl phthalates in the rat. Toxicol. Appl. Pharmacol. (1980), 54: 392-398.

Foster, P. M.D., Lake, B. G., Thomas, L. V., Cook, M. V., and Gangolli, S. D. Studies on the testicular effects and zinc excretion produced by various isomers of monobutyl-o-phthalate in the rat. Chem.Biol. Interact. (1981), 34: 233-238.

Foster, P. M.D., Lake, B. G., Cook, M. W., Thomas, L. V., and Gangolli, S. D. Structure-activity requirements for the induction of testicular atrophy by butyl phthalates in immature rats: Effects on testicular zinc content. Adv. Exp. Medicine Biol. (1982), 136A: 445-452.

Foster, P. M.D., Mylchreest, E., Gaido, K. W., and Sar, M. Effects of phthalate esters on the developing reproductive tract of male rats. Hum. Reprod. Update (2001), 7: 231-235.

Gazouli, M., Yao, Z., Boujard, N., Corton, C. J., Culty, M., and Papadopoulus, V. Effect of peroxisome proliferators on Leydig cell peripheral-type benzodiazepine receptor gene expression, hormonestimulated cholesterol transport and steroidogenesis: Role of the peroxisome proliferator-activator receptor a. Endocrinology (2002), 143: 2571-2583.

Gray, E. L., Jr., Ostby, J., Furr, J., Price, M., Veermachaneni, R. D.N., and Parks, L. Perinatal exposure to the phthalates DEHP, BBP, and DINP, but not DEP, DMP, or DOTP, alters sexual differentiation of the male rat. Toxicol. Sci. (2000), 58: 350-365.

Hanway, R. H., and Evans, P. F. Read-across of toxicological data in the notification of new chemicals. Toxicol. Lett. (2000), 116(Suppl. 1): 61.

Hauser, R., Duty, S., Godfrey-Bailey, L., and Calafat, A. M. Medications as a source of human exposure to phthalates. Environ. Health Persp. (2004), 112: 751-753.

Higuchi, T. T., Palmer, J. S., Gray, L. E., Jr., and Veeramachaneni, R. D.N. Effects of dibutyl phthalate in male rabbits following in utero, adolescent, or postpubertal exposure. Toxicol. Sci. (2003), 72: 301313.

Heindel, J. J., Gulati, D. K., Mounce, R. C., Russell, S. R., and Lamb, J. C. Reproductive toxicity of three phthalic acid esters in a continuous breeding protocol. In Appl. Toxicol, (1989), 12: 508-518.

Höfer, T., Gerner, I., Gundert-Remy, U., Liebsch, M., Schulte, A., Spielmann, H., Vogel, R., and Wettig, K. Animal testing and alternative approaches for the human health risk assessment under the proposed new European chemicals regulation. Arch. Toxicol. (2004), 78: 549-564.

Hulzebos, E. M., and Posthumus, R. (Q)SARs: Gatekeepers against risk on chemicals? SAR QSAR Environ. Res. (2003), 14: 285-316.

Hulzebos, E. M., Janssen, P. A.H., Maslankiewicz, L., Meijerink, M. C.M., Muller, J. J.A., Pelgrom, S. M.G., Verdam, L., and Vermeire, T. G. The application of structure-activity relationships in human hazard assessment: A first approach RIVM report 601516008, Bilthoven, the Netherlands, (2001).

IPCS Global assessment of the state-of-the science of endocrine disruptors WHO PCS ECD 02.2. World Health Organization, (2002)

http://www.who.int/ipcs/publications/new_issues/endocrine_disruptors/en.

IPCS Concise international chemical assessment document 52, Diethyl phthalate World Health Organization: Geneva, (2003). 
Jones, H. B., Garside, D. A., Liu, R., and Roberts, J. C. The influence of phthalate esters on Leydig cell structure and function in vitro and in vivo. Exp. Mol. Pathol. (1993), 58: 179-193.

Kluwe, W. M. Overview of phthalate ester pharmacokinetics in mammalian species. Environ. Health Perspect. (1982), 45: 3-10.

Koch, H. M., Rossbach, B., Drexler, H., and Angerer, J. Internal exposure of the general population to DEHP and other phthalates-Determination of secondary and primary phthalate monoester metabolites in urine. Environ. Res. (2003), 93: 177-185.

Lamb, J. C., Chapin, R. E., Teague, J., Lawton, A. D., and Reel, J. R. Reproductive toxicity of four phthalate esters: Structure-activity relationships. Toxicol. Appl. Pharmacol. (1987), 88: 255-269.

Latini, G., De Felice, C., Presta, G., Del Vecchio, A., Paris, I., Ruggeri, F., and Mazzeo, P. In utero exposure to di-(2-ethylhexyl) phthalate and duration of human pregnancy. Environ. Health Perspect. (2003), 111: 1783-1785.

Lee, J., Park, J., Jang, B., and Knudsen, T. B. Altered expression of genes related to zinc homeostasis in early mouse embryos exposed to di-2-ethylhexyl phthalate. Toxicol. Lett. (2004), 152: 1-10.

Lee, K. Y., Shibutani, M., Takagi, H, Kato, N., Takigami, S., Uneyama, C., and Hirose, M. Diverse developmental toxicity of di-n-butyl phthalate in both sexes of rat offspring after maternal exposure during period from late gestation through lactation. Toxicology (2004), 203: 221-238.

Lehman, K. P., Philips, S., Sar, M., Foster, P. M.D., and Gaido, K. W. Dose-dependent alternations in gene expression and testosterone synpaper in the fetal testes of male rats exposed to di(n-butyl) phthalate. Toxicol. Sci. (2004), 81: 60-68.

Lovenkamp-Swan, T., and Davis, B. J. Mechanism of phthalate ester toxicity in the female reproductive system. Environ. Health Perspect. (2003), 111(2): 139-145.

McKee, R. H., El-Hawari, M., Stoltz, M., Pallas, F., and Lington, A. W. Absorption, disposition and metabolism od di-isononyl phthalate (DINP) in F-344 rats. J. Appl. Toxicol. (2002), 22: 293-302.

Ministry of Housing Spatial Planning and Environment Strategy on management of substances April 2001. The Hague, the Netherlands, (2001) http://www2.minvrom.nl/Docs/internationaal/soms_engels.pdf (accessed 12 2004).

Moore, R. W., Rudy, T. A., Lin, T. M., Ko, K., and Peterson, R. E. Abnormalities of sexual development in male rats with in utero and lactational exposure to the antiandrogenic plasticizer di(2ethylhexyl)phthalate. Environ. Health Perspect. (2001), 109: 229-237.

Mylchreest, E., Sar, M., Cattley, R., and Foster, P. M.D. Disruption of androgen-regulated male reproductive development by di(n-butyl)phthalate during late gestation in rats is different from flutamide. Toxicol. Appl. Pharmacol. (1999), 156: 81-95.

Mylchreest, E., Wallace, D. G., Cattley, R. C., and Foster, P. M.D. Dose-dependent alternations in androgen-regulated male reproductive development in rats exposed to di(n-butyl) phthalate during late gestation. Toxicol. Sci. (2000), 55: 143-151.

Mylchreest, E., Sar, M., Wallace, D. G., and Foster, P. M.D. Fetal testosterone insufficiency and abnormal proliferation of Leydig cells and gonocytes in rats exposed to di(n-butyl)phtahalate. Reprod. Toxicol. (2002), 16: 19-28.

Nef, S., and Parada, L. F. Hormones in male sexual development. Genes Dev. (2000), 14: 3075-3086. NTP NIEHS Environ. Health Perspect. Suppl Di-n-pentylphthalate. NTIS PB86118999 AS, (1997a), 105(1) http://ehp.niehs.nih.gov/members/1997/Suppl-1/phth180.html (accessed 01 2005).

NTP NIEHS Environ. Health Perspect. Suppl Di-n-propylphthalate. NTIS PB85247856 AS, (1997), 105(1) http://.ehp.niehs.gov/members/1997/Suppl-1/phth180.html (accessed 01 2005).

NTP-CERHR NTP-CERHR monograph on the potential human reproductive and developmental effects of di-n-butyl phthalate (DBP) National Toxicology Program (NTP), Center for the Evaluation of Risks to Human Reproduction (CERHR). NTP-CERHR Monographs no. 004-2003, (2003a) http://library.niehs.nih.gov/whatsnew/2003/books/nbks0803.htm\#cerhrdbp.

NTP-CERHR NTP-CERHR monograph on the potential human reproductive and developmental effects of di-n-hexyl phthalate (DnHP) National Toxicology Program (NTP), Center for the Evaluation of Risks to Human Reproduction (CERHR); NTP-CERHR Monographs no. 007-2003, (2003b) http://library.niehs.nih.gov/whatsnew/2003/books/nbks0803.htm\#cerhrdbp.

NTP-CERHR NTP-CERHR monograph on the potential human reproductive and developmental effects of di-n-octyl phthalate (DnOP) National Toxicology Program (NTP), Center for the Evaluation of Risks to Human Reproduction (CERHR); NTP-CERHR Monographs no. 006-2003, (2003c) http://library.niehs.nih.gov/whatsnew/2003/books/nbks0803.htm\#cerhrdbp.

OECD Manual for investigation of HPV chemicals OECD Secretariat, (2004)

http://www.oecd.org/document/7/0,2340,en_2649_34379_1947463_1_1_1_1,00.html (accessed 12 2004).

OECD-HPV Di(2-ethylhexyl)terephthalate SIDS initial assessment profile, (2003) http://cs3-

hq.oecd.org/scripts/hpv/. 
OECD-HPV OECD draft SIDS initial assessment report for category: high molecular weight phthalate esters, (2004a) http://cs3-hq.oecd.org/scripts/hpv/.

OECD-HPV Draft SIDS initial assessment report for diisoheptyl phthalate, (2004b) for SIAM 20 (19-22 April 2005)http://cs3-hq.oecd.org/scripts/hpv/.

OECD-HPV Diallyl phthalate Draft SIDS initial assessment profile (SIAP), (2004c) http://cs3hq.oecd.org/scripts/hpv/.

OECD-HPV 1,2-Benzenedicarboxylic acid, di-C6-8-branched alkyl esters, C7-rich (diisoheptyl phthalate ester) Draft SIDS initial assessment profile (SIAP), (2004d) http://cs3-hq.oecd.org/scripts/hpv/.

Oishi, S., and Hiraga, K. Testicular atrophy induced by phthalic acid esters: Effects on testosterone and zinc concentrations. Toxicol. Appl. Pharmacol. (1980), 53: 35-41.

Park, J. D., Habeebu, S. S.M., and Klaassen, C. D. Testicular toxicity of di-(2-ethylhexyl) phthalate in young Sprague-Dawley rats. Toxicology (2002), 171: 105-115.

Parks, L. G., Ostby, J. S., Lambright, C. R., Abbott, B. D., Klinefelter, G. R., Barlow, N. J., and Gray, L. E., Jr. The plasticizer diethylhexyl phthalate induces malformations by decreasing fetal testosterone synpaper during sexual differentiation in the male rat. Toxicol Sci (2000), 58: 339-349.

Pedersen, F., De Bruijn, J., Munn, S., and Van Leeuwen, K. Assessment of additional testing needs under REACH. Effects of (Q)SARs, risk based testing and voluntary industry initiatives European Commission, IHCP, (2003) http://ecb.jrc.it (accessed 1 2005).

Pennanen, S., Tuovinen, K., Huuskonen, H., Kosma, V.-M., and Komulainen, H. Effects of 2ethylhexanoic acid on reproduction and postnatal development in Wistar rats. Fundam. Appl. Toxicol. (1993), 21: 204-212.

Ritter, E. J., Scott, W. J., Jr., Randall, J. L., and Ritter, J. M. Teratogenicity of di(2-ethylhexyl) phthalate, 2-ethylhexanol, 2-ethylhexanoic acid, and valproic acid, and potentiation by caffeine. Teratology (1987), 35: 41-46.

Salazar, V., Castillo, C., Ariznavarreta, C., Campon, R., and Tresguerres, J. A.F. Effect of oral intake of dibutyl phthalate on reproductive parameters of long Evans rats and pre-pubertal development of their offspring. Toxicology (2004), 205: 131-137.

Sharpe, R. Hormones and testis development and the possible adverse effects of environmental chemicals. Toxicol. Lett. (2001), 120: 221-232.

Sharpe, R. M., and Irvine, D. S. How strong is the evidence of a link between environmental chemicals and adverse effects on human reproductive health? Br. Med. J. (2004), 328: 447-451.

Shono, T., and Suita, S. Dose-dependent effects ester of phthalate ester testicular descent in pre- and postnatal rats. Urol. Res. (2003), 1: 293-296.

Shultz, V. D., Philips, S., Sar, M., Foster, P. M.D., and Gaido, K. W. Altered gene profiles in fetal rat testes after in utero exposure to di(n-butyl) phthalate. Toxicol. Sci. (2001), 64: 233-242.

Silva, M. J., Barr, D. B., Reidy, J. A., Kato, K., Malek, N. A., Hodge, C. C., Hurtz, D., III, Calafat, A. M., Needham, L. L., and Brock, J. W. Glucuronidation patterns of common urinary and serum monoester phthalate metabolites. Arch. Toxicol. (2003), 77: 561-567.

Silva, M. J., Barr, D. B., Reidy, J. A., Malek, N. A., Hodge, C. C., Caudill, S. P., Brock, J. W., Needham, L. L., and Calafat, A. M. Urinary levels of seven phthalate metabolites in the U.S. population from the National Health and Nutrition Examination Survey (NHANES) 1999-2000. Environ. Health Perspect. (2004a), 112: 331-338.

Silva, M. J., Reidy, J. A., Herbert, A. R., Preau, J. L., Jr., Needham, L. L., and Calafat, A. M. Detection of phthalate metabolites in human amniotic fluid. Bull. Environ. Contam. Toxicol. (2004b), 72: 12261231.

Skakkebæk, N. E., Rajpert-De Meyts, E., and Main, K. M. Testicular dysgenesis syndrome: An increasingly common developmental disorder with environmental aspects. Hum. Reprod. (2001), 5 : 972-978.

Thomas, J. A., and Thomas, M. J. Biological effects of di-(2-ethylhexyl) phthalate and other phthalic acid esters. Crit. Rev. Toxicol. (1984), 13: 283-317.

Thompson, C. J., Ross, S. M., and Gaido, K. W. Di (n-butyl) phthalate impairs cholesterol transport and stereidogenesis in the fetal rat testis through a rapid and reversible mechanism. Endocrinology (2004), 145: 1227-1237.

U.S. Environmental Protection Agency Development of chemical categories in the HPV challenge program Draft document. Office of Pollution Prevention and Toxics, (1999) http://www.epa.gov/chemrtk/categuid.htm (accessed 12 2004).

Van Der Jaght, K., Munn, S., Torslow, J., and De Bruijn, J. Alternative approaches can reduce the use of test animals under REACH. Addendum to the report "Assessment of additional testing needs under REACH. Effects of (Q)SARs, risk based testing and voluntary industry initiatives." European Commission, Joint research Centre, Institute for Health and Consumer Protection. Report EUR 21405EN, (2004) http://ecb.jrc.it. 
Critical Reviews in Toxicology, 36:695-726, 2006

Voss, C., Zerban, H., Bannasch, P., and Berger, M. R. Lifelong exposure to di-(2-ethyhexyl)-phthalate induces tumours in liver and testes of Sprague-Dawley rats. Toxicology (2004), 206: 359-371.

Walker, J. D., Jaworska, J., Comber, M. H.I., Schultz, T. W., and Dearden, J. C. Guidelines for developing and using quantitative structure-activity relationships. Environ. Toxicol. Chem. (2003), 22: 1653-1665.

WHO Environmental Health Criteria 131, Diethylhexyl phthalate WHO IPS: Geneva, (1992) http://www.inchem.org/document/ehc/ehc/ehc131.htm.

Wilson, V. S., Lambright, C., Furr, J., Ostby, J., Wood, C., Held, G., and Gray, E. L., Jr. Phthalate ester-induced gubrnacular lesions are associated with reduced Insl3 gene expression in the fetal rat testis. Toxicol. Lett. (2004), 146: 207-215.

Zacharewski, T. R., Meek, M. D., Clemons, J. H., Wu, Z. F., Fielden, M. R., and Matthews, J. B. Examination of the in vitro and in vivo estrogenic activities of eight commercial phthalate esters. Toxicol. Sci. (1998), 46: 282-293. 